\title{
Eco-thermodynamics of hydrogen production by high- temperature electrolysis using solid oxide cells
}

Type of article: Original article

Authors:

Andi Mehmeti ${ }^{a^{*}}$, Athanasios Angelis-Dimakis ${ }^{\mathrm{b}}$, Carlos Boigues Muñoz ${ }^{\mathrm{c}, \mathrm{d}}$, Marco Graziadio ${ }^{\mathrm{d}, \mathrm{e}}$, Stephen J.

McPhail $^{\mathrm{e}}$

${ }^{a}$ DIST, Parthenope University of Naples, Naples, Italy

${ }^{b}$ School of Applied Sciences, University of Huddersfield, Queensgate, Huddersfield, HD1 3DH, UK

${ }^{c}$ DIISM, Polytechnic University of Marche, Ancona 60121, Italy

${ }^{d}$ DAFNE, Tuscia University, Viterbo 01100, Italy

${ }^{e}$ DTE-PCU-SPCT, ENEA C.R. Casaccia, Via Anguillarese 301, 00123 Rome, Italy

\section{Author names and affiliations.}

Author \#1 (Corresponding author)

Andi Mehmeti

Current Affiliation

1. Department of Science and Technology, Parthenope University of Naples, 80143 Naples, Italy

E-Mail: andi.mehmeti@ uniparthenope.it; Tel: +39 327-556-3659

Author \#2

Athanasios Angelis-Dimakis

Current Affiliation

2. School of Applied Sciences, University of Huddersfield, Huddersfield HD1 3DH, UK

E-Mail: a.angelisdimakis@hud.ac.uk; Tel: 01484473656

Author \#3

\section{Carlos Boigues Muñoz}

Current Affiliation

3. DTE-PCU-SPCT, ENEA C.R. Casaccia, Via Anguillarese 301, 00123 Rome, Italy

E-Mail : carlos.boigues@enea.it; Tel: +39 06330484869

Author \#4

Marco Graziadio

Current Affiliation

4. DTE-PCU-SPCT, ENEA C.R. Casaccia, Via Anguillarese 301, 00123 Rome, Italy

E-Mail : marco.graziadio@enea.it; Tel: +39 06330484004

Author \#5

Stephen J. McPhail

Current Affiliation

5. DTE-PCU-SPCT, ENEA C.R. Casaccia, Via Anguillarese 301, 00123 Rome, Italy

E-Mail : stephen.mcphail@enea.it; Tel: +39063 30484926 


\title{
Eco-thermodynamics of hydrogen production by high-temperature electrolysis using solid oxide cells
}

Andi Mehmeti ${ }^{a^{*}}$, Athanasios Angelis-Dimakis ${ }^{b}$, Carlos Boigues Muñoz $^{\text {c,e }}$, Marco Graziadio ${ }^{\text {d,e }}$, Stephen J. McPhail ${ }^{\mathrm{e}}$

${ }^{a}$ DIST, Parthenope University of Naples, Naples, Italy

${ }^{b}$ School of Applied Sciences, University of Huddersfield, Queensgate, Huddersfield, HD1 3DH, UK

${ }^{c}$ DIISM, Polytechnic University of Marche, Ancona 60121, Italy

${ }^{d}$ DAFNE, Tuscia University, Viterbo 01100, Italy

${ }^{e}$ DTE-PCU-SPCT, ENEA C.R. Casaccia, Via Anguillarese 301, 00123 Rome, Italy

*Corresponding author: Andi Mehmeti; Email: andi.mehmeti@ uniparthenope.it; Tel: +39 327-556-3659

\begin{abstract}
In this study, Solar Energy Demand (SED), Cumulative Exergy Extraction from the Natural Environment (CEENE), and LCA-ReCiPe 2016 (using both midpoint and endpoint modeling) life cycle impact assessment methods has been used to assess the performance of hydrogen $\left(\mathrm{H}_{2}\right)$ production with renewable and non-renewable electricity sources via high-temperature Solid Oxide Electrolysis Cells. The analysis identified most relevant impact categories, life cycle stages, and processes, both from a thermodynamic and an environmental viewpoint. Electrolysis with nonrenewable energy is characterized by the greatest environmental burdens, however, renewable energy systems also have considerable environmental impacts, some of which are significant. While no perfect electricity source exists, a growing portion of the renewable-based electricity production in the grid mix is an attractive option to lower environmental impacts of $\mathrm{H}_{2}$ production. Irrespective of the evaluation method, the contribution analysis from different life-cycle stages shows and confirm that the major contributor to the environmental burdens is the electricity supply. The manufacturing stage has high relevance for mineral and metal resources and toxicity-related impacts. Calculations of grid-based electrolysis life cycle environmental impacts in some European countries showed that significant variations. For example, global warming potential per $\mathrm{kgH}_{2}$ produced vary between 3.31 and $48.24 \mathrm{kgCO}_{2}$. Trade-off analysis between the midpoint and endpoint indicators revealed that water consumption, global warming, and particulate matter formation, play a major role in the ranking of electricity supply options. The findings suggest that all potential impacts both at the midpoint and endpoint level should be considered to ensure robust results of the LCA evaluation, a fair comparison between pathways towards more transparent and evidence-based decisions. Towards that end, a further country site-specific assessment with optimization strategies and integration of traditional LCA with resource accounting (thermodynamic metrics) will need to be developed to explore additional valuable insights towards sustainable electrolytic $\mathrm{H}_{2}$ production systems.
\end{abstract}

Keywords: power-to-gas, LCA, hydrogen, electrolysis, resource footprint; Eco-thermodynamics 


\title{
Highlights:
}

- A resource-based impact assessment using thermodynamic indicators was performed.

- It was complemented by a midpoint and endpoint life cycle impact assessment.

- Electricity supply dominates the result from different life-cycle stages.

- Sustainable hydrogen production is achieved with renewable electricity supply.

- Water use and global warming dominate the impacts on human health and ecosystems.

\begin{abstract}
Abbreviations
Exergetic life cycle assessment (ELCA); Emergy life cycle analysis (EmLCA); Global warming potential (GWP); Stratospheric ozone depletion (ODP); Ionizing radiation (IRP); Photochemical oxidant formation: human health (HOFP); Photochemical oxidant formation: ecosystem quality (EOFP); Human toxicity potential: cancer $\left(\mathrm{HTP}_{\mathrm{c}}\right)$; Human toxicity potential: non-cancer $\left(\mathrm{HTP}_{\mathrm{nc}}\right)$; Terrestrial ecotoxicity (TETP); Freshwater ecotoxicity (FETP); Marine ecotoxicity (METP); Freshwater eutrophication potential (FEP); Fine particulate matter formation (PMFP); Terrestrial acidification (TAP); Land use (LOP); Water consumption potential (WCP); Mineral resource scarcity (SOP); Fossil resource scarcity (FFP); Combined heat and power (CHP); Life cycle assessment (LCA); Life cycle inventory (LCI); Human health (HH); Ecosystem quality (EQ); Resource scarcity (RA); Solar Energy Demand (SED); Cumulative exergy extractions from the natural environment (CEENE); High-temperature electrolysis (HTE); Solid oxide electrolysis cells (SOEC)
\end{abstract}

\section{Introduction}

Hydrogen $\left(\mathrm{H}_{2}\right)$ has received a great deal of attention as a clean energy carrier from both scientists and policy-makers (Ball and Weeda, 2015). The vision of using hydrogen is one advocated as a possible solution to the development of new and more efficient energy conversion systems, as an answer to the growing concerns regarding greenhouse gas emissions, energy security, and decoupling of economic growth from environmental impacts (Marban and Valdes-Soleis, 2007). However, sustainable development of a large-scale hydrogen economy will require potential green solutions simultaneously pursuing environmental quality, economic prosperity and social benefits (Turner, 2004; Marban and Valdes-Soleis, 2007).

Hydrogen can be produced through a variety of chemical, electrochemical and biological methods using both renewable and non-renewable sources of energy (Dincer and Acar, 2014). In the last few years, the interest in poly-generation electrochemical systems based on reversible fuel cell is exponentially increasing, due to their higher capacity and efficiency compared to competing 
technologies (Laguna-Bercero, 2012). Solid oxide cells operating in electrolysis mode (referred as

Solid oxide cells operating in electrolysis mode-SOEC) not only generate $\mathrm{H}_{2}$ from steam, with a very high efficiency but can also co-electrolyze carbon dioxide $\left(\mathrm{CO}_{2}\right)$ and steam and produce synthesis gas. This represents an attractive route for achieving long-term reduction of $\mathrm{CO}_{2}$ emissions by storing excess renewable electricity into methane and other liquid organic carriers (Gahleitner, 2013).

Hydrogen and fuel-cell systems are promoted as sustainable pathways to generate green $\mathrm{H}_{2}$, however, realizing the full environmental potential of hydrogen and fuel cell technology requires research and development on product life cycle sustainability (Masoni and Zamagni, 2011; Mehmeti et al., 2016a, 2016b). By analyzing impacts throughout the product life cycle using system life-cycle thinking (LCT) and assessment (LCA) an interactive knowledge about environmental trade-offs and impacts among various processes is established. In the end, the results from life cycle-based assessments help to benchmark the environmental performance, prioritize commercial environmental improvements and promote sustainable hydrogen production strategies.

The number of LCA studies on $\mathrm{H}_{2}$ production has increased rapidly in order to guide challenging decisions, address sustainability problems and help the selection between alternative technology paths (Valente et al., 2016). To date, a limited research is published on LCA of SOEC hydrogen production, addressing only the common environmental issues such as greenhouse gas emissions, energy use, and acidification potential. Depending on the source of the electricity used for the electrolysis process, there are impact categories and indicators that need to be assessed for a holistic overview of the complex issue of environmental sustainability. In order to understand the full range of potential environmental impacts, Ulgiati et al. (2006) suggest that it is vital carrying out an assessment with different impact assessment methods representing both the upstream (depletion of many different forms of resources, renewable or non-renewable) and the downstream impacts (environmental consequences of the emissions). A multi-impact LCA-based analysis provides valuable insights into the trade-offs between life cycle stages and impacts and helps to prioritize 
research activities and to potentially avert unintended consequences. To generate an enduring breakthrough for a highly promising but lower readiness level technology, this research combines different environmental impact assessment methods to develop a set of life cycle indicators and conduct a holistic environmental sustainability assessment of HTE via SOEC technology (Figure 1). The aim of the present study is twofold. Firstly, it advances the scope of the current LCA studies of $\mathrm{H}_{2}$ production by providing useful information about natural resource consumption (global demand for environmental support provided by the biosphere and efficient use of work potential of resources all over the supply chain) using cutting-edge resource consumption assessment methods based on thermodynamics. In most recent literature, thermodynamic indicators based on exergy (Exergetic life cycle assessment - ELCA) and emergy accounting (emergy-based life cycle assessment - EmLCA), integrated with LCA principles, are used together to better understand overall environmental sustainability performance of products or services (Buonocore et al., 2015; Ehtiwesh et al., 2016; Hernandez et al., 2017). Environmental impacts resulting from resource use were analyzed by means of EmLCA using the solar energy demand (SED) method (Rugani et al., 2011) and an extended ELCA using the Cumulative Exergy Extracted from the Natural Environment (CEENE) method (Dewulf et al., 2007). Secondly, with the use of state-of-the-art impact assessment method LCA-ReCiPe 2016 (Huijbregts et al., 2017), a multi-criteria environmental profile of life cycle impacts at both the midpoint (problem-oriented) and the endpoint (damage-oriented) level is presented. The midpoint indicators denote a potential impact located somewhere along the cause-impact pathway between emissions/resource consumption and the endpoint level. Endpoints are defined as the final damage to the human health, ecosystem diversity and resource availability, which are caused by environmental impacts at midpoint level (Huijbregts et al., 2016). The LCA-ReCiPe 2016 model is a life cycle impact model used to gain insight into environmental effects, including and effects on human health, terrestrial ecosystems and freshwater ecosystems alongside other environmental impacts. Life-cycle assessment of water consumption for $\mathrm{H}_{2}$ production has become of major interest in sustainability studies because of its 
great relevance to the comparison of the environmental performance of products (Mehmeti et al., 2018a).

Given the limited research on LCA studies on high-temperature electrolysis, the final outcome of the paper is to provide a useful multi-impact environmental profile of the SOEC electrolysis technology with different applied energy sources (Figure 1). The results provide a better understanding of the strengths and weaknesses of electrolysis with SOEC in terms of resource footprint and environmental effects and a more comprehensive viewpoint for the researchers and policymakers.

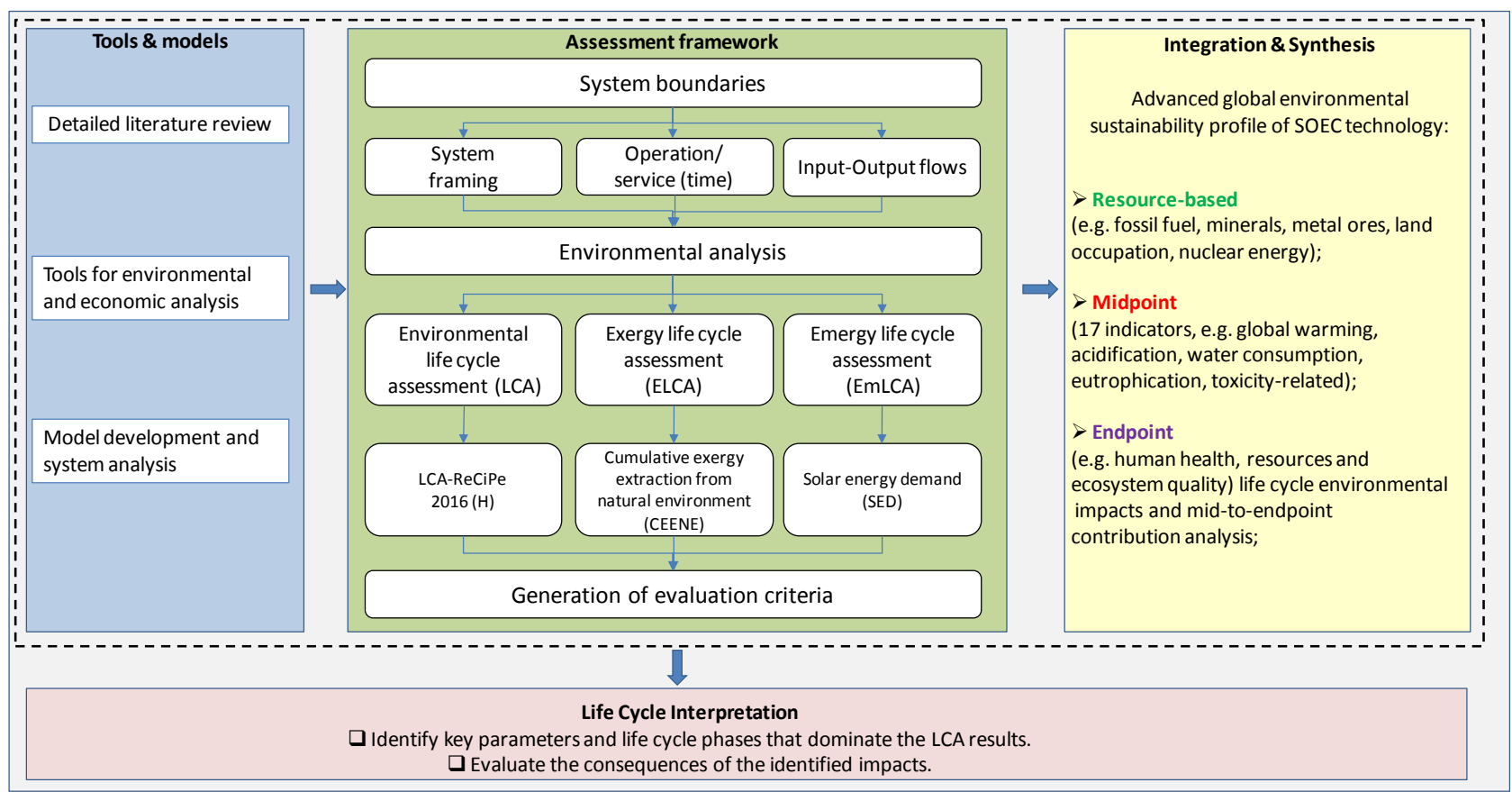

Figure 1. Schematic representation of the adopted conceptual framework for environmental sustainability assessment.

\section{Material and methods}

The following section presents all the preparatory steps before conducting the life cycle impact assessment. These include the framing of the system, by determining its boundaries and the functional unit of the analysis, and the population of the life cycle inventory, by listing all the involved inflows and outflows and estimating their quantity per functional unit. 


\subsection{System framing}

The SOEC technology (Figure 2) is a highly promising, bi-directional, cross-vector technology, converting electricity to hydrogen (electrolysis mode, SOEC) and converting it back into electricity (fuel cell mode, SOFC). Steam electrolysis (1) uses electricity to split steam into oxygen and hydrogen. SOECs must operate at temperatures high enough for the solid oxide membranes to function properly (about 600 to $850^{\circ} \mathrm{C}$, compared to $\mathrm{PEM}$ electrolyzers, which operate at $70-90^{\circ} \mathrm{C}$, and commercial alkaline electrolyzers, which operate at $100-150^{\circ} \mathrm{C}$ ).

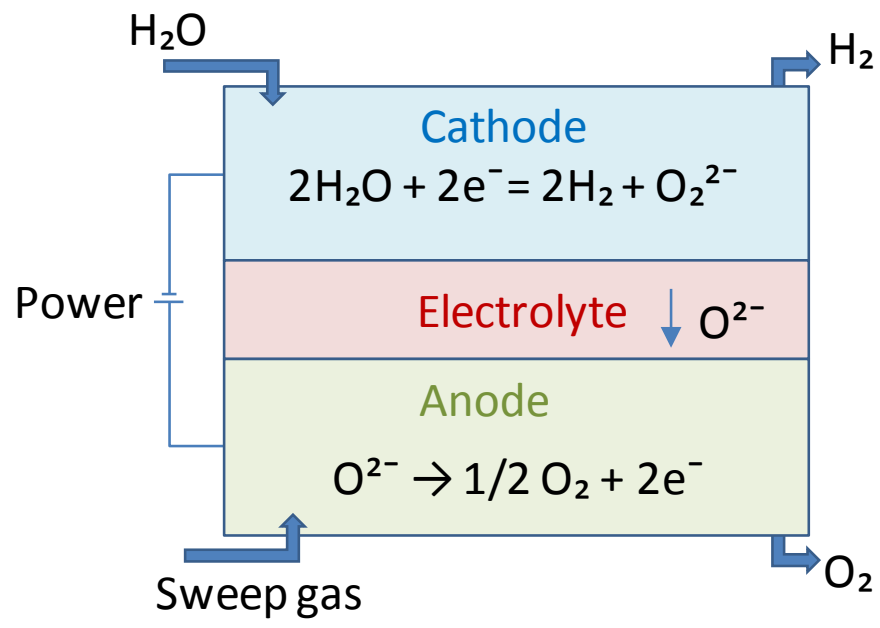

Figure 2. The configuration and operating principle of the SOEC unit (redrawn from (Minh and Mogensen (2013)).

High-temperature electrolysis using SOEC ensures enormous thermodynamic advantages since the energy is supplied in a mixed form of electricity and heat (Valderrama, 2016). SOECs can effectively use heat available from various sources, including waste heat. Theoretically, up to $40 \%$ of the energy required to produce hydrogen via steam electrolysis can be supplied as heat (Bhandari et al., 2014). 


$$
\mathrm{H}_{2} \mathrm{O} \rightarrow \mathrm{H}_{2}+\frac{1}{2} \mathrm{O}_{2}
$$

The focus of this LCA study is a SOEC system with a plant capacity of $100 \mathrm{~kg}$ of hydrogen per day, using electricity provided from the grid. The diagram of the investigated system is shown in Figure 3, where the main input and output flows, resources and processes are identified. The considered system is distinguished into the foreground system and the background system. The system describes the cradle-to-grave production of hydrogen and consists of the following phases: construction of SOEC, operation, and maintenance. The system boundary is defined using a thermodynamic hierarchy at four levels $(\mathrm{A}+\mathrm{B}+\mathrm{C}+\mathrm{D})$. The level $\mathrm{A}$ includes the biosphere-related processes that provide the primary resources (i.e. traces back the primary energy and material resources to include the planetary processes). The level B (technosphere) includes all energy and materials conversion processes that are needed to support infrastructure processes in the background system (level C). The background system supports the foreground system and its processes. It deals with almost all material and energy flows going to and coming from the foreground system. The foreground system (level D) comprises all processes related to the production and operation of the SOEC itself and includes the direct inputs (water, energy, and other materials) of all stages, which are used to produce the functional unit, i.e. $1 \mathrm{~kg}$ of $\mathrm{H}_{2}$ at the plant gate. Downstream processes such as compression, storage, and delivery pathways are not taken into account. Co-product oxygen is released into the environment; hence, no multi-functionality was modeled within the system boundaries. 


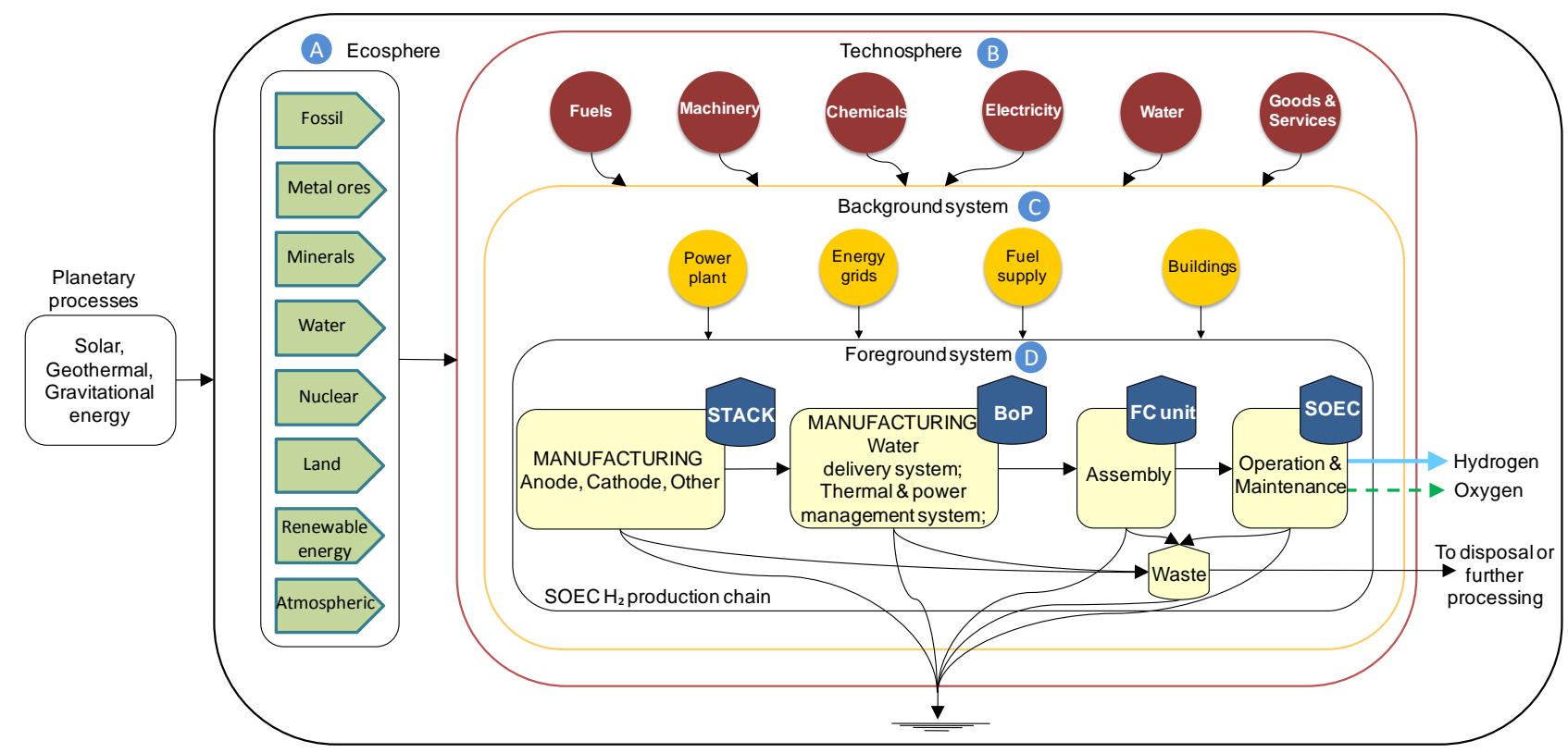

Figure 3. System boundary and process flows of HTE-SOEC hydrogen production system. RR: renewable resources; NRR: non-renewable resources; FC: Fuel Cell; SOEC: Solid Oxide Electrolysis Cell (Modified from (Mehmeti et al., 2018c).

\subsection{System life cycle inventory}

The life cycle inventory (LCI) tracked the input-output flows associated with the system under analysis (

Table 1). For the calculation of the electricity-related environmental impact, the base case considers typical values for medium voltage grid-supplied electricity in Italy. The LCA case studies of hightemperature electrolysis are mainly based on nuclear energy and occasionally supported by renewable electricity (Valente et al., 2016). To obtain a complete assessment, the whole spectrum of primary energy sources (fossil, nuclear, renewable) for electricity production must be considered (IAEA, 2013). Every energy source has different environmental characteristics, bringing with the different benefits - and very different problems. Therefore, gaseous hydrogen production based on eight different electricity pathways (

Table 1) was modeled using imported commodities from the Ecoinvent database (v.3). The electricity needed for electrolysis was modeled using renewable (solar, wind, hydropower, and biomass) or non-renewable (grid, coal, natural gas, and nuclear-based) pathways under European 
system boundary conditions. Individual electricity sources were modeled in order to assess the sensitivity of the results to the electricity used for electrolysis (Simons and Bauer, 2011).

Table 1. Input-output flows for production of $1 \mathrm{~kg}$ of hydrogen with high-temperature solid oxide electrolysis (SOEC).

\begin{tabular}{llcc}
\hline Unit of product & Material & Data input & Unit \\
\hline \multirow{5}{*}{ Operation } & Deionized water & 10.84 & $\mathrm{~kg}$ \\
& Electricity supply ${ }^{\text {a }}$ & 40.3 & $\mathrm{kWh}$ \\
& Heat, Natural gas, at boiler modulating & 5.24 & $\mathrm{kWh}$ \\
& Products/Services Hydrogen, at SOEC plant & 1 & $\mathrm{~kg}$ \\
& By-Product Oxygen, at SOEC plant & 7.8 & $\mathrm{~kg}$ \\
\hline & Yttria stabilized zirconia (YSZ) & $4.41 \times 10^{-4}$ & $\mathrm{~kg}$ \\
& Lanthanum Strontium Manganite (LSM) & $2.64 \times 10^{-4}$ & $\mathrm{~kg}$ \\
& Nickel Oxide (Nickel, 99.5\%, at plant) & $2.22 \times 10^{-4}$ & $\mathrm{~kg}$ \\
& Ethanol, at plant/RER & $6.49 \times 10^{-4}$ & $\mathrm{~kg}$ \\
& Polyethylene glycol, at plant/RER & $1.30 \times 10^{-4}$ & $\mathrm{~kg}$ \\
& 1-butanol, propylene hydroformylation, at plant/RER & $7.35 \times 10^{-5}$ & $\mathrm{~kg}$ \\
& Phthalic anhydride, at plant/RER & $7.35 \times 10^{-5}$ & $\mathrm{~kg}$ \\
& Chromium, at regional storage/RER & $8.10 \times 10^{-3}$ & $\mathrm{~kg}$ \\
& Chromium steel 18/8, at plant/RER & $4.68 \times 10^{-3}$ & $\mathrm{~kg}$ \\
& Sheet rolling, chromium steel/RER & $4.68 \times 10^{-3}$ & $\mathrm{~kg}$ \\
& Electricity, medium voltage, production UCTE, at grid & $1.90 \times 10^{-4}$ & $\mathrm{MWh}$ \\
& Alumina-silica insulation material & $1.30 \times 10^{-3}$ & $\mathrm{~kg}$ \\
& Transport, all modes ${ }^{\mathrm{b}}$ & $3.19 \times 10^{-3}$ & $\mathrm{tkm}$ \\
\hline Reinforcing Steel, at plant/RER & $1.32 \times 10^{-4}$ & $\mathrm{~kg}$ \\
& Sheet rolling, steel/RER & $1.32 \times 10^{-4}$ & $\mathrm{~kg}$ \\
& Chromium, at regional storage/RER & $5.39 \times 10^{-4}$ & $\mathrm{~kg}$ \\
Aluminium, at plant/RER & $5.82 \times 10^{-5}$ & $\mathrm{~kg}$ \\
Copper, at regional storage/RER & $2.81 \times 10^{-4}$ & $\mathrm{~kg}$ \\
& Electricity, medium voltage, production UCTE, at grid & $1.15 \times 10^{-6}$ & $\mathrm{MWh}$ \\
Transport, all modes ${ }^{\mathrm{b}}$ & $2.02 \times 10^{-4}$ & $\mathrm{tkm}$ \\
Heating, sanitary equipment Cogen unit 160kWe/RER & $1.17 \times 10^{-6}$ & $\mathrm{MJ}$ \\
Construction work, Cogen unit 160kWe/RER & $5.46 \times 10^{-6}$ & $\mathrm{unit}$ \\
Light fuel oil, boiler 100kW, non-modulating/RER & $1.30 \times 10^{-2}$ & $\mathrm{MJ}$ \\
& Building, multi-storey/RER & $4.90 \times 10^{-6}$ & $\mathrm{~m}$ \\
Building, hall, steel construction/CH & $8.07 \times 10^{-7}$ & $\mathrm{~m}{ }^{2}$ \\
\hline
\end{tabular}

${ }^{a}$ Lifecycle unit processes linked to the Ecoinvent: Grid - Electricity, medium voltage, at grid/IT; Nuclear - Electricity, nuclear, at power plant/UCTE; Wind power - Electricity, at wind power plant/RER; Natural gas, high pressure, at consumer/RER; Solar power - electricity, production mix photovoltaic, at plant/IT; Electricity, hydropower, at power plant/IT; Electricity, hard coal, at power plant/IT; Water, deionized, at plant/CH;

${ }^{\mathrm{b}}$ A distance of $200 \mathrm{~km}$ was considered for all transportation systems: i) Transoceanic freight ship; ii) Freight, rail; iii) lorry >16t, fleet average; iv) Lorry 3.5-16t, fleet average; v) Passenger car; vi) Barge

This LCA is partially based on the observed experimental data of a 5-cell SOEC short stack tested in fuel cell and electrolysis mode in the frame of the SOCTESQA (Solid Oxide Cell and Stack Testing, Safety and Quality Assurance) project (Graziadio et al., 2016). A single operating point has been taken into consideration in this paper, more particularly the thermo-neutral voltage at $750{ }^{\circ} \mathrm{C}$ 
with an inlet gas composition of $80 \mathrm{~mol} \% \mathrm{H}_{2} \mathrm{O}$ and $20 \mathrm{~mol} \% \mathrm{H}_{2}$ and a conversion rate of $83 \%$. The

abovementioned conditions yield a voltage of $1.286 \mathrm{~V}$ per cell and a current density of $-0.7 \mathrm{~A} / \mathrm{cm}^{2}$ attending to the experimental results. European solid oxide cell manufacturers offer similar products regarding cell material and size; thus, a planar negative-electrode supported cell with $121 \mathrm{~cm}^{2}$ of the active area (assumed in this work) can be considered to be the "standard". Based on these data, approximately 1320 cells are needed to fulfill the required daily production of $\mathrm{H}_{2}$ in the refueling station, meaning that $143.8 \mathrm{~kW}$ are necessary to power the SOEC stack. Accounting for the needs of the balance of plant, this figure can be increased to $150 \mathrm{~kW}$. A priori, the $80 \mathrm{~mol} \%$ only external thermal power needed in the system is the one necessary to heat the inlet flows from room temperature to the nominal operating temperature of the stack (i.e. $750^{\circ} \mathrm{C}$ ). The conversion rate of $83 \%$ corresponds to a steam inlet into the stack equal to $1086 \mathrm{~kg} / \mathrm{day}$. In terms of specific energy requirements (without accounting stack degradation), this equals to $36 \mathrm{kWh} / \mathrm{kgH}_{2}$ for the electrical side and $4.75 \mathrm{kWh} / \mathrm{kgH}_{2}$ (assuming an efficiency of the heat exchange of 95\%) for the heating side. The average stack degradation rate was assumed to be $0.5 \%$ per $1,000 \mathrm{~h}$. Thus, energy requirements in terms of electricity and heat are $40.3 \mathrm{kWh} / \mathrm{kgH}_{2}$ and $5.24 \mathrm{kWh} / \mathrm{kgH}_{2}$, respectively.

The inventory data for manufacturing the electrolyzer module were retrieved using a merged inventory of a generic SOFC planar system (Staffell et al., 2012; Mehmeti et al., 2018b) and scaled to the required hydrogen output (

Table 1). The data for the stack material was scaled up linearly, while the materials for the balanceof-plant were scaled with an exponential factor of 0.7 (Gerboni et al., 2008). As a general rule, casespecific primary data is used to describe the foreground processes, while more generic information is used for background processes (Masoni and Zamagni, 2011). To be as representative as possible, an updated inventory as described by Primas (2007) was developed. Stack service lifetime of 5 years was used as a base case. The lifetime of system and BoP components was considered 20 years. The inventory data for the use of stack and BoP are normalized to the functional unit by 
dividing the amount of activity data with the unit process by the respective lifetime. The maintenance was calculated as a function of stack replacement.

\subsection{Environmental impact assessment methods}

The environmental impact assessment is performed using a variety of life cycle impact assessment methods, that complement each other and provided a holistic view of the environmental performance of the process. Both resource-driven and emission-driven indicators are used to identify hotspots, most relevant life cycle stages and processes. In the first case, emergy and exergybased method are used, whereas in the second case, a more conventional LCA is performed using the LCA-ReCiPe2016 methodology and both midpoint and endpoint indicators.

\subsubsection{Resource-driven LCIA}

Natural resources have received significant attention in recent years resulting in the development of a wide range of resource depletion indicators within LCA (Rørbech et al., 2014). Emergy analysis, driven by principles of thermodynamics and systems ecology, is recommended for life cycle studies to associate a product with its dependencies on all upstream environmental and resource flows using a common unit of energy (Ingwersen, 2011). Emergy provides indicators that expand the evaluation process to the larger space and time scales of the biosphere (Sciubba and Ulgiati, 2005). In this study, the solar energy demand (SED) method (Rugani et al., 2011) was used to build the ecoprofile of each pathway within LCA. The SED indicator is estimated on the basis of the broader emergy approach (Odum, 1996), although it has a few shortcomings because it does not take into account components, such as human labor, information, and local ecosystem services (Rugani et al., 2011). This choice to simplify the calculation procedure was made in order to facilitate the comparison with other approaches within the LCA framework. The SED method consists of calculating the cumulative amount of each resource ultimately consumed in the technosphere order 
to produce the functional unit (Arbault et al., 2014). It is expressed in the corresponding physical unit and converted to emergy units (i.e. the emergetic cost of extraction and use of each required resource). The system boundaries are chosen as similar to those of a life-cycle assessment, as all resources needed during the life cycle of a product or process are accounted for. In SED analysis, the specific SED scores of commodity life cycles (Rugani et al., 2011), derived from the emergy concept, are applied as characterization factors to LCI values. The SED of the system's output is given as:

$$
\operatorname{SED}_{\mathrm{p}}=\sum_{\mathrm{i}} \mathrm{SED}_{\mathrm{i}} \times \mathrm{M}_{\mathrm{p}, \mathrm{i}}
$$

\section{Where:}

- $\mathrm{SED}_{\mathrm{p}}$ represents the total solar energy directly and indirectly required to produce the good or service $\mathrm{p}$ (expressed as $\mathrm{MJ}_{\mathrm{se}}$-eq, Megajoules of equivalent solar energy),

- $\mathrm{SED}_{\mathrm{i}}$ is the solar energy conversion factor of the reference flow of resource $\mathrm{i}$ (expressed in $\mathrm{MJ}_{\mathrm{se}}$-eq/unit), and

- $\mathrm{M}_{\mathrm{p}, \mathrm{i}}$ is the flow of resource $\mathrm{i}$ (e.g. measured in $\mathrm{kg}, \mathrm{m}^{3}$, MJ etc.) involved as input in the production and functioning of the SOEC unit.

The SED is a reasonably well-accounted method; however, using SED values as published by Rugani et al. (2011), limits the outcome to only one indicator, the one needed for the goals of the present study. The use of only one indicator involves the risk of losing some insight regarding the interactions of the system with the environment, and especially its relation to ecosystem services (Wilfart et al., 2013).

For the exergy-based life cycle impact assessment, the Cumulative Exergy Extracted from the Natural Environment (CEENE) method was applied to calculate the resource footprint (Dewulf et al., 2007). CEENE is recognized as a complete advanced accounting method (Liao et al., 2012; Sala et al., 2016) and is applied in many scientific studies. 


$$
\operatorname{CEENE}_{j}=\sum_{i=1}^{184}\left(X_{i} \times a_{i, j}\right)
$$

Where:

- $\mathrm{CEENE}_{\mathrm{j}}$ is the cumulative exergy extracted from the natural environment for a product $\mathrm{j}$ (in $\left.\mathrm{MJ}_{\mathrm{ex}}-\mathrm{eq}\right)$,

- $\mathrm{X}_{\mathrm{i}}$ is the factor of the reference flow $\mathrm{i}\left(\mathrm{X}_{\mathrm{i}}\right.$ in $\left.\mathrm{MJ}_{\mathrm{ex}} / \mathrm{kg}, \mathrm{MJ}_{\mathrm{ex}} / \mathrm{MJ}, \mathrm{MJ}_{\mathrm{ex}} / \mathrm{m}^{3}\right)$,

- $\mathrm{a}_{\mathrm{i}, \mathrm{j}}$ is the cumulative amount of reference flow $\mathrm{i}$ (e.g. $\mathrm{kg}, \mathrm{MJ}, \mathrm{m}^{3}$, etc.) necessary to obtain product $\mathrm{j}$.

The CEENE 2014 updated characterization factors adapted for Ecoinvent database (Taelman et al., 2014) and the SimaPro software were used for the assessment.

The results for SED and CEENE are presented for eight categories of resources extracted from the natural environment: atmospheric, renewable resources, fossil fuels, nuclear energy, metal ores, minerals, water resources and land resources.

\subsubsection{Emission-driven LCIA}

The most recent version of the life cycle impact assessment method of the ReCiPe LCA methodology (LCA-ReCiPe 2016) was used to assess the environmental impacts of $\mathrm{H}_{2}$ production via SOEC. The LCA-ReCiPe 2016 (Huijbregts et al., 2017) is a Life Cycle Impact Assessment (LCIA) method, which comprises harmonized category indicators at the midpoint and the endpoint level. Both midpoint (seventeen) and endpoint (three) indicators were used. The study addresses the following midpoint environmental impact categories: Global warming potential (GWP), stratospheric ozone depletion (ODP), ionizing radiation (IRP), photochemical oxidant formation: 
human health (HOFP), photochemical oxidant formation: ecosystem quality (EOFP), human

toxicity potential: cancer (HTPc), human toxicity potential: non-cancer (HTPnc), terrestrial ecotoxicity (TETP), freshwater ecotoxicity (FETP), marine ecotoxicity (METP), freshwater eutrophication potential (FEP), fine particulate matter formation (PMFP); terrestrial acidification (TAP), land use (LOP), water consumption potential (WCP), mineral resource scarcity (SOP), and fossil resource scarcity (FFP). These impact categories contribute differently to the three damage categories at endpoint level: Damage to human health $(\mathrm{HH})$, ecosystem quality (EQ) and resource scarcity (RA). The application of LCA by using midpoint and endpoint interpretation simplifies the interpretation of the LCIA results and contributes to a better understanding of the environmental impacts (Bare et al., 2000). Any imprudent usage of the two approaches may affect the assessment results and thus lead to misleading findings (Dong and Ng, 2014). The environmental impacts in ReCiPe can be calculated by means of three cultural perspectives: Individualist, Hierarchist, and Egalitarian. The choice of cultural perspective reflects different choices on effect and damage modeling (Huijbregts et al., 2017). In this study, the hierarchist perspective (without any normalization and weighting) was used since it is based on the most common policy principles with regard to time-frame (100-year timeframe is the most frequently used) and referenced to in the ISO standards on LCA as the default version of the method (Goedkoop et al., 2013).

\section{Results and discussion}

Interpretation of LCA results has been systematized as follows: (i) Resource use based on thermodynamics using solar energy demand (SED) and Cumulative Exergy Extracted from the Natural Environment (CEENE) life cycle impact assessment methods; (ii) Midpoint and endpoint impact assessment results using LCA-ReCiPe 2016; (iii) Mid-to-endpoint impact category analysis, i.e. to identify and compare the contribution of midpoint impact categories on endpoint level; (iv) Life-cycle contribution analysis for all LCIA methods; (v) Comparison of SOEC life cycle performance with other hydrogen production methods. 


\subsection{Resource-consumption life cycle impact assessment}

Exergy (CEENE) and emergy-oriented (SED) cradle-to-gate life-cycle resource indicators based on thermodynamics were used to quantify the impact on the environment through the extraction and/or consumption of natural resources for $\mathrm{H}_{2}$ production via SOEC with different electricity sources. The former characterizes the previous effort spent by the ecosphere (Figure 3) in generating resources, while the latter corresponds to the resources extracted from the ecosphere to be used in the technosphere in order to support the foreground system (Huysman et al., 2015; Liao et al., 2012). The results for each electricity pathway are presented in Figure 4 for SED and Figure 5 for CEENE. Numerical results and impact contribution to CEENE and SED per life-cycle phase are presented in Appendix A.

The SED life cycle impact assessment shows that nuclear and wind-based electrolysis have the lowest (direct or indirect) energy requirements for $1 \mathrm{~kg} \mathrm{H}_{2}$ product $\left(7.65 \times 10^{6}\right.$ and $1.06 \times 10^{7} \mathrm{MJ}_{\mathrm{se}^{-}}$ $\mathrm{eq} / \mathrm{kgH}_{2}$, respectively). As it can be seen from Figure 4 the highest share of the total SED impact for all pathways is related to fossil fuel consumption followed by metals and minerals. The demand for metal ores and minerals is dominating the score of SED for wind and solar-powered electrolysis. However, hydrogen produced via the coal electricity uses higher fossil resources, thus having the highest SED footprint. The use of conventional fuels such as coal and natural gas in the electricity mix will likely raise the impacts of electricity supply since a larger amount of non-renewable resources along the production chain is needed. 


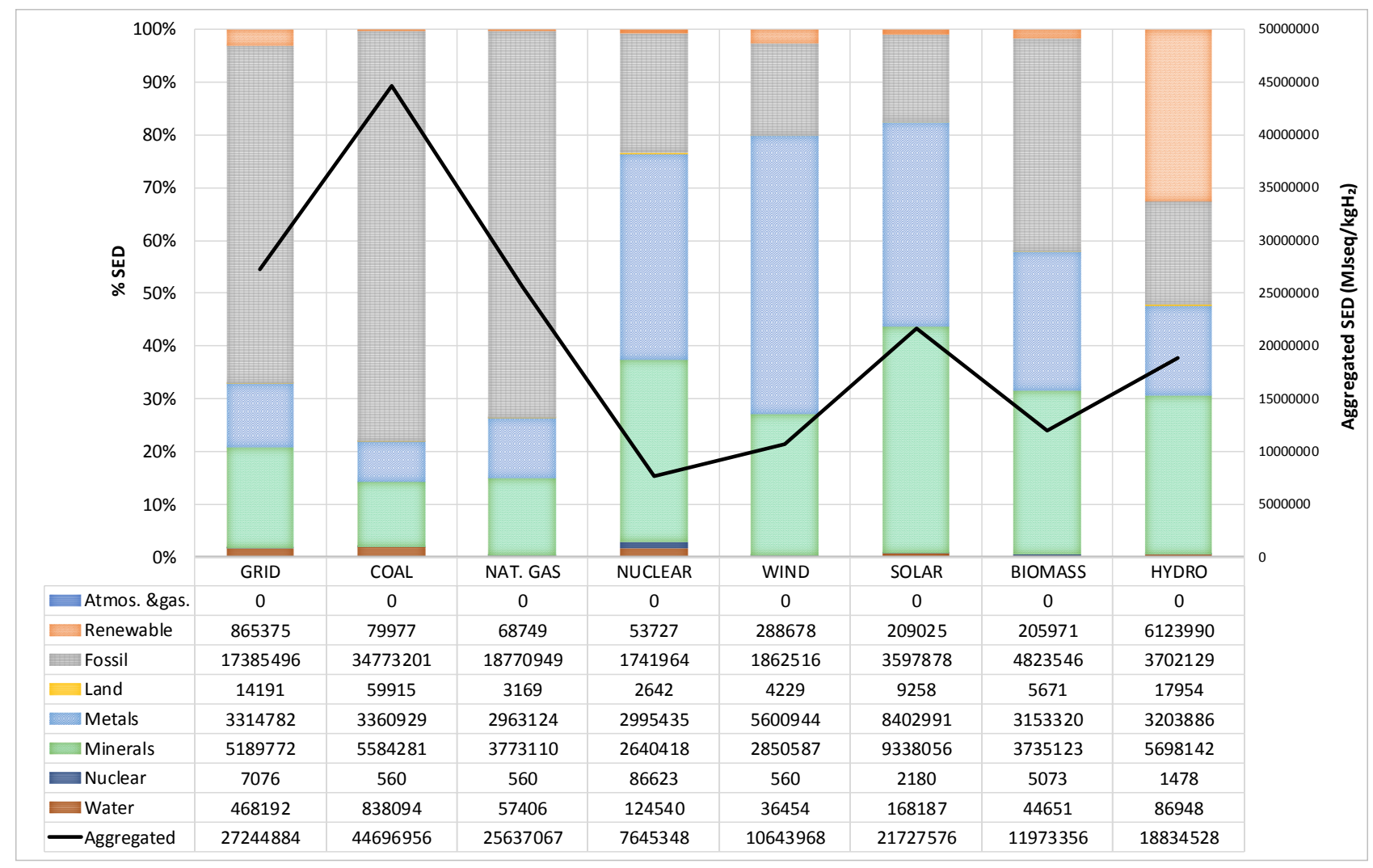

Figure 4. Relative contribution of each resource group to solar energy demand (SED) per $1 \mathrm{~kg}$ $\mathrm{H}_{2}$ under different electricity pathways.

Regarding resource based CEENE, the highest share of the total CEENE impact is related to fossil resources for five electricity pathways, followed by nuclear and renewable energy (Figure 5). The life cycle CEENE footprint ranges from $102.3 \mathrm{MJ}_{\mathrm{ex}}-\mathrm{eq} / \mathrm{kgH}_{2}$ for solar to $668 \mathrm{MJ}_{\mathrm{ex}}-\mathrm{eq} / \mathrm{kgH}_{2}$ for wind-powered electrolysis. Wind energy electrolysis has the highest total CEENE score; however, only $6.2 \%$ of that demand is related to non-renewable energy resources. For CEENE analysis renewable resources have a particular dominant contribution to the wind and hydro-powered electrolysis. Except for the abiotic renewable resource group, electrolysis with solar power has a higher resource footprint than wind-based electrolysis, due to the more intensive manufacturing processes of PV panels and the higher land footprint. 


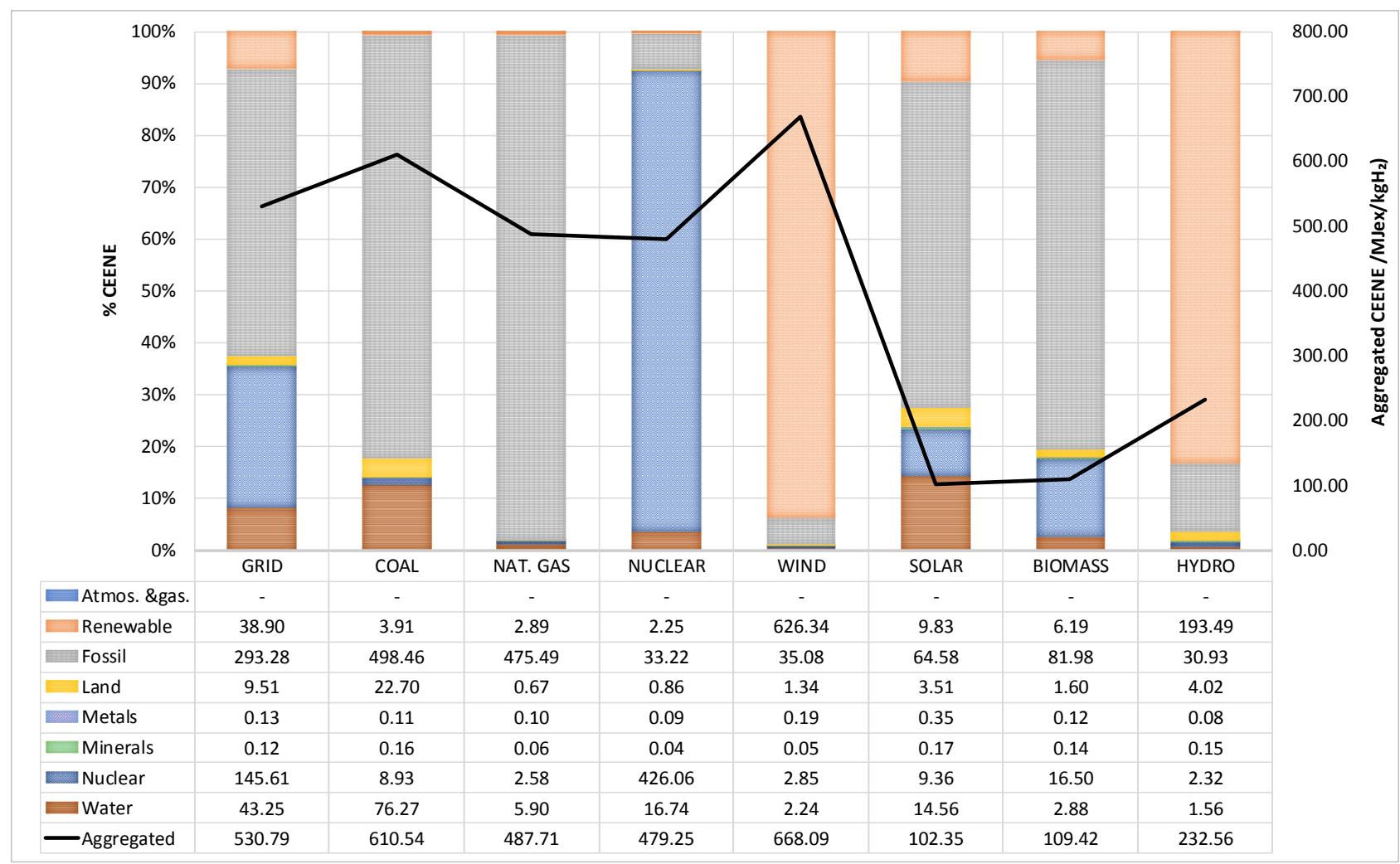

Figure 5. Relative contribution of each resource group to cumulative exergy extracted from the natural environment (CEENE) per $1 \mathrm{~kg} \mathrm{H}_{2}$ under different electricity pathways.

The resource-driven life cycle assessments show that non-renewable resources (in particular fossil resources) have a dominant contribution to all seven resource indicators. From the perspective of sustainability, the primary energy demand from non-renewable resources is more meaningful since it reflects the consumption of depleting natural energy resources and is greatly contributing to the global warming (Fischer et al., 2005; Liao et al., 2012). Overall, the resource consumption analysis shows that a sustainable hydrogen strategy needs more efficient and novel energy-saving processes and increasing the penetration of renewable power. It clearly shows the potential of resource conservation and the advantage of renewable power compared to conventional pathways. Similar conclusions were observed from Brown and Ulgiati (2002), who demonstrated quantitatively with a larger number of integrated indicators (e.g. Emergy Yield Ratio, Emergy Investment Ratio, Environmental Loading Ratio, Emergy Sustainability Index) that the so-called renewable energy sources (geothermal, hydroelectric, and wind plants) had higher sustainability compared to thermal plants (natural gas, oil, and coal). In the long-term, production systems with a high percentage of 
renewable emergy are likely to be closer to sustainability and were able to survive economic

\subsection{LCA-ReCiPe 2016 life cycle impact assessment}

The LCA-ReCiPe 2016, a harmonized LCIA method, was used to generate a multi-impact environmental profile, i.e. a score list with different environmental impact categories (Table 2) that express the impact on the environment at midpoint and endpoint level. For the midpoint indicators, all electrolysis routes have advantages and drawbacks, and there is no single production route that results in an optimal environmental performance. Comparative LCA indicates that conventional energy technologies have significantly higher environmental impacts per unit of generation.

Global warming potential (GWP) is the impact category analyzed by several studies. Italian grid produces hydrogen with a global warming potential (GWP) of $25.64 \mathrm{~kg} \mathrm{CO}_{2}-\mathrm{eq} / \mathrm{kgH}_{2}$. The highest GWP value is observed for coal-based electrolysis $\left(43.95 \mathrm{~kg} \mathrm{CO}_{2}\right.$-eq/ $\left.\mathrm{kgH}_{2}\right)$ being over 30 times higher than hydro, wind and nuclear-coupled HTE systems, which are characterized by the lowest GWP (respectively 0.72, 2.26 and $2.11 \mathrm{~kg} \mathrm{CO}_{2}$-eq/ $/ \mathrm{kg} \mathrm{H}_{2}$ ). Patyk et al. (2013) highlight that nuclearpowered HTE is slightly better than wind-powered HTE regarding GWP. To the contrary, Utgikar and Thiesen (2006) in their analysis found that renewable energy sources (wind and hydropower) have marginally lower impacts than nuclear-powered HTE. For GWP impact category, hydro or wind electrolysis were identified as the most environmental feasible hydrogen production technologies by Bhandari et al. (2014).

Midpoint analysis indicates that using renewable or nuclear energy technologies, either separate from the grid, or as a growing portion of the grid mix, is a possible option to produce extremely low global warming potential. For non-renewable energy generation, environmental indicators strongly favor nuclear systems because of their higher energy density as well as higher capacity factors. However, this requires dynamic analysis of the whole system i.e. including environmental impacts associated with nuclear fuel management and decommissioning of nuclear waste (in this study the 
harnessing of nuclear energy for the production of $\mathrm{H}_{2}$ was limited to the generation of electricity for

electrolysis). The inclusion of such impacts will provide a holistic environmental analysis and decide whether nuclear based HTE is better than the other technologies. Ionizing radiation category was dominant under the nuclear pathway (Table 2) and is an important difference between nuclear and non-nuclear hydrogen production technologies (Bhandari et al., 2014; Giraldi et al., 2015). Wind and solar-based electrolysis will deliver a significant benefit in terms of ionizing radiation footprint ( 0.3 and $0.98 \mathrm{kBq}$ Co60-eq/ $\mathrm{kg} \mathrm{H}_{2}$ ) in comparison with nuclear-based electrolysis (44.73 $\mathrm{kBq}$ Co60-eq/ $\mathrm{kg} \mathrm{H}_{2}$ ). Exposures to ionizing radiation will likely cause an increased risk of cancer and severe hereditary effects, consequently leading to potential human health damage (Table 3).

For solar PV based electrolysis GWP vary by over a factor of two in respect to wind and nuclear route $\left(4.63 \mathrm{~kg} \mathrm{CO}_{2}\right.$-eq/ $\mathrm{kg} \mathrm{H}$ ). In addition, hydrogen production via electrolysis with solar power has marginally higher terrestrial ecotoxicity (TETP) and mineral scarcity (SOP) impact than other electricity routes due to the infrastructure chain and the second water consumption potential impacts. Wind and solar power have the highest impact in terms of mineral scarcity, which is mainly associated with the infrastructure chain. The LCA-ReCiPe 2016 analysis shows similar results and trends to those observed in the SED and CEENE analysis where solar-powered electrolysis has a higher environmental footprint compared to wind due to the more intensive manufacturing processes of PV modules. Predominantly, renewable technologies require higher initial investments in infrastructure than fossil-based power systems (Hertwich et al., 2015). Increasing resource efficiency and recyclability are the main strategies of sustainable technology development since the large-scale deployment of renewable energy is expected to cause increased demand for critical mineral resources (Viebahn et al., 2015).

Biomass-based electrolysis scores a moderately higher GWP (14.36 $\mathrm{kg} \mathrm{CO}_{2}$-eq/kg $\mathrm{H}_{2}$ ) than those for solar, hydro or wind electrolysis. The electrolysis with biomass energy has the highest stratospheric ozone depletion (ODP) impacts due to the nitrous oxide emissions connected with upstream processes, i.e. on-field biomass production and burning in biomass CHP systems. This 
increased emission of ozone-depleting substances negatively affecting human health (Table 3). At a 1 global scale, ODP represents the second main contributor to damage to human health. 
Table 2. Midpoint and endpoint environmental performance indicators of HTE-SOEC hydrogen production (data referred to $1 \mathrm{~kg} \mathrm{H}_{2}$ ).

\begin{tabular}{|c|c|c|c|c|c|c|c|c|c|}
\hline \multirow{2}{*}{$\begin{array}{l}\text { Impact } \\
\text { Category }\end{array}$} & \multirow[b]{2}{*}{ Unit } & \multicolumn{8}{|c|}{ Electricity source } \\
\hline & & $\begin{array}{c}\text { ITALIAN } \\
\text { GRID }\end{array}$ & COAL & NATURAL GAS & NUCLEAR & WIND & SOLAR & BIOMASS & HYDRO \\
\hline \multicolumn{10}{|c|}{ Midpoint environmental impact categories } \\
\hline GWP & $\mathrm{kg} \mathrm{CO}_{2}$-eq & 25.64 & 43.95 & 28.93 & 2.11 & 2.26 & 4.63 & 14.36 & 0.72 \\
\hline ODP & kg CFC11-eq & $1.19 \times 10^{-5}$ & $1.23 \times 10^{-5}$ & $1.02 \times 10^{-5}$ & $1.05 \times 10^{-6}$ & $7.79 \times 10^{-7}$ & $2.21 \times 10^{-6}$ & $3.80 \times 10^{-5}$ & $2.61 \times 10^{-7}$ \\
\hline IRP & kBq Co60-eq & 3.92 & 0.96 & 0.28 & 44.73 & 0.30 & 0.98 & 1.76 & 0.25 \\
\hline HOFP & $\mathrm{kg} \mathrm{NO}_{\mathrm{x}}-\mathrm{eq}$ & 0.0501 & 0.1201 & 0.0369 & 0.0029 & 0.0026 & 0.0080 & 0.0124 & 0.0015 \\
\hline PMFP & kg PM2.5-eq & 0.0256 & 0.0643 & 0.0050 & 0.0020 & 0.0016 & 0.0042 & 0.0050 & 0.0010 \\
\hline EOFP & $\mathrm{kg} \mathrm{NO}_{\mathrm{x}}-\mathrm{eq}$ & 0.0511 & 0.1209 & 0.0384 & 0.0032 & 0.0029 & 0.0085 & 0.0129 & 0.0017 \\
\hline TAP & $\mathrm{kg} \mathrm{SO} \mathrm{S}_{2}-\mathrm{eq}$ & 0.0955 & 0.2309 & 0.0274 & 0.0045 & 0.0044 & 0.0135 & 0.0297 & 0.0025 \\
\hline FEP & kg P-eq & 0.00601 & 0,02995 & 0,00050 & 0,00052 & 0,00065 & 0,00268 & 0,00095 & 0,00040 \\
\hline TETP & kg 1.4DCB-eq & 0.0091 & 0.0040 & 0.0010 & 0.0037 & 0.0017 & 0.0211 & 0.0026 & 0.0006 \\
\hline FETP & kg 1.4DCB-eq & 0.214 & 0.877 & 0.031 & 0.060 & 0.058 & 0.284 & 0.129 & 0.024 \\
\hline METP & kg 1.4DCB-eq & 0.32 & 1.22 & 0.05 & 0.09 & 0.08 & 0.43 & 0.18 & 0.04 \\
\hline HTPc & kg 1.4DCB-eq & 0.89 & 2.23 & 0.54 & 0.52 & 0.60 & 0.71 & 0.60 & 0.46 \\
\hline HTPnc & kg 1.4DCB-eq & 222.01 & 906.17 & 26.50 & 49.00 & 52.99 & 338.01 & 94.08 & 19.15 \\
\hline LOP & $\mathrm{m}^{2} \times \mathrm{y}$ crop-eq & 0.083 & 0.424 & 0.014 & 0.016 & 0.033 & 0.053 & 0.037 & 0.009 \\
\hline SOP & $\mathrm{kg} \mathrm{Cu}-\mathrm{eq}$ & 0.030 & 0.026 & 0.022 & 0.048 & 0.067 & 0.076 & 0.031 & 0.022 \\
\hline FFP & kg oil-eq & 7.59 & 10.65 & 10.41 & 0.70 & 0.75 & 1.39 & 1.77 & 0.18 \\
\hline WCP & $\mathrm{m}^{3}$ & 171.07 & 25.82 & 16.73 & 17.46 & 19.39 & 71.79 & 35.31 & 716.33 \\
\hline \multicolumn{10}{|c|}{ Endpoint environmental impact categories } \\
\hline $\mathrm{HH}$ & DALY & $3.40 \times 10^{-4}$ & $1.46 \times 10^{-4}$ & $6.30 \times 10^{-5}$ & $3.83 \times 10^{-5}$ & $4.24 \times 10^{-5}$ & $1.65 \times 10^{-4}$ & $9.14 \times 10^{-5}$ & $1.53 \times 10^{-3}$ \\
\hline EQ & Species $\times$ y & $1.89 \times 10^{-6}$ & $5.24 \times 10^{-7}$ & $2.83 \times 10^{-7}$ & $2.09 \times 10^{-7}$ & $2.35 \times 10^{-7}$ & $9.55 \times 10^{-7}$ & $4.91 \times 10^{-7}$ & $9.29 \times 10^{-6}$ \\
\hline RA & $\$$ & 2.767 & 1.291 & 3.707 & 0.236 & 0.248 & 0.441 & 0.61 & 0.215 \\
\hline
\end{tabular}


Hydropower is intrinsically a cleaner power generation route, however, has the highest absolute

value of water consumption potential (WCP). The environmental impacts of hydro-powered electrolysis will mainly depend on hydropower facilities data sets. Hydropower with no storage of water (as considered in this study) tends to be the most attractive and the water is still available for agricultural purposes after the electricity is generated (Varun et al., 2009). The water consumption is crucial for hydrogen production pathways, gaining additional importance in the LCA, because of the cause-and-effect chain of water consumption, and leading to greater impacts on human health and ecosystem quality (both terrestrial and freshwater quality) of high water-demanding supply chains. Consequently, regarding the endpoint categories, (Table 2) electrolysis with hydropower electricity supply has the highest impact on human health and ecosystem quality, but the lowest to resource scarcity. Accordingly, calculation of performance at both midpoint and endpoint levels gives good insight into the expected environmental effects and complement the conclusions of a study given the trade-offs between different environmental impact categories. Apart from WCP, the hydropower powered electrolysis has negative effects on terrestrial ecosystems (EOFP) and freshwater eutrophication (FEP) since high land-use requirements are associated with hydropower reservoirs (Hertwich et al., 2015), while toxicity related impacts are due to the construction of the hydropower plant (Hanafi and Riman, 2015). Hydropower environmental impacts may be higher than those of some fossil fuel sources during the first years after reservoir creation, typically due to the production and construction of the technology and/or its supporting infrastructure (Steinhurst et al., 2012). In addition, the ability of hydropower to contribute to climate change mitigation is sometimes questioned, knowing that greenhouse gas emissions resulting from the degradation of biogenic carbon in hydropower reservoirs are ignored or poorly understood, possibly leading to a bias in technology comparisons (Hertwich, 2013). 


\subsection{Mid-to-endpoint analysis}

The LCA-ReCiPe 2016 endpoint indicators (Appendix A) have been calculated to also highlight the contribution of each midpoint indicators to the three endpoint indicators and the overall environmental sustainability (Table 3). The midpoint to endpoint analysis guides decision makers to select relevant midpoint categories for further examination. Generally speaking, modeling the cause-effect chain to the damages are associated with high uncertainty. The contribution of mid-toendpoint analysis indicates that the water consumption, global warming, particulate matter formation, and fossil fuel depletion was the most important impact categories. The analysis shows that for the conventional electricity generation pathways, such as coal and natural gas, the GWP is greatly affecting the damage to human health ( 28 and $43 \%$, respectively), indicating that the magnitude of endpoint impacts of these pathways mainly depends on fuel supply and consumption, process efficiency, and the corresponding type and quantity of emissions (i.e. $\mathrm{CO}_{2}, \mathrm{CH}_{4}$, and $\mathrm{N}_{2} \mathrm{O}$ ) in each stage. For the other electricity pathways, the numerical results of this study show that water consumption potential dominated the impact on the human health and ecosystem quality impact categories. The use of renewable energy sources leads to an increased importance of the water consumption impact since renewable energy sources usually have low global warming, particulate matter formation, and ozone depletion potential. The extraction of $1 \mathrm{~m}^{3}$ of water has a higher impact than the GWP of $1 \mathrm{~kg}$ of $\mathrm{CO}_{2}$ in human health when converted from midpoint to endpoint (2.22E0.6 DALY $/ \mathrm{m}^{3}$ consumed vs. 9.28E-07 DALY $/ \mathrm{kgCO}_{2}$-eq). The same applies also to the terrestrial and aquatic ecosystems impact categories. The water consumption rate and location play a fundamental role in endpoint LCA environmental impact categories since the effects of water consumption will have a very high impact in water-scarce areas (Huijbregts et al., 2017). Hence, environmental damage due to water consumption, in addition to other impact categories shall be used in future LCA studies of electrolysis to map the influence of life-cycle stages on the environment. 
Table 3. Weighted contribution of midpoint categories on the endpoint level for each electricity pathway.

\begin{tabular}{|c|c|c|c|c|c|c|c|c|}
\hline Midpoint categories & GRID & COAL & NG & NUCLEAR & WIND & SOLAR & BIOMASS & HYDRO \\
\hline \multicolumn{9}{|c|}{ Human Health (DALY) } \\
\hline GWP & $7.75 \%$ & $27.94 \%$ & $42.62 \%$ & $4.87 \%$ & $4.72 \%$ & $2.55 \%$ & $14.52 \%$ & $0.11 \%$ \\
\hline ODP & $0.00 \%$ & $0.00 \%$ & $0.01 \%$ & $0.00 \%$ & $0.00 \%$ & $0.00 \%$ & $0.02 \%$ & $0.00 \%$ \\
\hline IRP & $0.00 \%$ & $0.01 \%$ & $0.00 \%$ & $1.00 \%$ & $0.01 \%$ & $0.00 \%$ & $0.02 \%$ & $0.00 \%$ \\
\hline HOFP & $0.01 \%$ & $0.07 \%$ & $0.05 \%$ & $0.01 \%$ & $0.01 \%$ & $0.00 \%$ & $0.01 \%$ & $0.00 \%$ \\
\hline PMPF & $4.90 \%$ & $27.64 \%$ & $4.84 \%$ & $3.09 \%$ & $2.19 \%$ & $1.53 \%$ & $3.31 \%$ & $0.04 \%$ \\
\hline HTPc & $0.78 \%$ & $4.92 \%$ & $2.46 \%$ & $3.91 \%$ & $4.13 \%$ & $1.28 \%$ & $1.92 \%$ & $0.09 \%$ \\
\hline HTPnc & $0.40 \%$ & $4.12 \%$ & $0.24 \%$ & $0.80 \%$ & $0.78 \%$ & $1.35 \%$ & $0.66 \%$ & $0.01 \%$ \\
\hline WCP & $86.15 \%$ & $35.30 \%$ & $49.77 \%$ & $86.33 \%$ & $88.16 \%$ & $93.28 \%$ & $79.54 \%$ & $99.75 \%$ \\
\hline \multicolumn{9}{|c|}{ Ecosystems $[$ Species $\times y$ ] } \\
\hline GWP & $4.2 \%$ & $23.5 \%$ & $28.7 \%$ & $2.7 \%$ & $2.6 \%$ & $1.3 \%$ & $8.1 \%$ & $0.1 \%$ \\
\hline EOFP & $0.4 \%$ & $3.0 \%$ & $1.7 \%$ & $0.2 \%$ & $0.1 \%$ & $0.1 \%$ & $0.3 \%$ & $0.0 \%$ \\
\hline TAP & $1.1 \%$ & $9.3 \%$ & $2.0 \%$ & $0.4 \%$ & $0.4 \%$ & $0.3 \%$ & $1.3 \%$ & $0.0 \%$ \\
\hline FEP & $0.2 \%$ & $3.5 \%$ & $0.1 \%$ & $0.1 \%$ & $0.2 \%$ & $0.2 \%$ & $0.1 \%$ & $0.0 \%$ \\
\hline TETP & $0.0272 \%$ & $0.0398 \%$ & $0.0164 \%$ & $0.0923 \%$ & $0.0374 \%$ & $0.1186 \%$ & $0.0268 \%$ & $0.0003 \%$ \\
\hline FETP & $0.0071 \%$ & $0.1156 \%$ & $0.0066 \%$ & $0.0185 \%$ & $0.0158 \%$ & $0.0203 \%$ & $0.0176 \%$ & $0.0002 \%$ \\
\hline METP & $0.0017 \%$ & $0.0245 \%$ & $0.0017 \%$ & $0.0042 \%$ & $0.0035 \%$ & $0.0046 \%$ & $0.0037 \%$ & $0.0000 \%$ \\
\hline LOP & $0.0 \%$ & $0.7 \%$ & $0.0 \%$ & $0.1 \%$ & $0.1 \%$ & $0.0 \%$ & $0.1 \%$ & $0.0 \%$ \\
\hline WCP & $94.0 \%$ & $59.8 \%$ & $67.4 \%$ & $96.4 \%$ & $96.6 \%$ & $97.9 \%$ & $90.0 \%$ & $99.9 \%$ \\
\hline \multicolumn{9}{|c|}{ Resources [\$] } \\
\hline SOP & $0.2 \%$ & $0.4 \%$ & $0.1 \%$ & $4.5 \%$ & $6.1 \%$ & $3.9 \%$ & $1.1 \%$ & $2.1 \%$ \\
\hline FFP & $99.8 \%$ & $99.6 \%$ & $99.9 \%$ & $95.5 \%$ & $93.9 \%$ & $96.1 \%$ & $98.9 \%$ & $97.9 \%$ \\
\hline
\end{tabular}

${ }^{\mathrm{a}}$ Global warming potential (GWP); Stratospheric ozone depletion (ODP); Ionizing radiation (IRP); Photochemical oxidant formation: human health (HOFP); Photochemical oxidant formation: ecosystem quality (EOFP); Human toxicity potential: cancer $\left(\mathrm{HTP}_{\mathrm{c}}\right)$; Human toxicity potential: non-cancer $\left(\mathrm{HTP}_{\mathrm{nc}}\right)$; Terrestrial ecotoxicity (TETP); Freshwater ecotoxicity (FETP); Marine ecotoxicity (METP); Freshwater eutrophication potential (FEP); Fine particulate matter formation (PMFP); Terrestrial acidification (TAP); Land use (LOP); Water consumption potential (WCP); Mineral resource scarcity (SOP); Fossil resource scarcity (FFP);

\subsection{Life-cycle stage contribution analysis}

To understand the influence of different phases of the supply chain, the life cycle contribution profile was generated for environmental impact categories, as presented in Appendix A. The results show that environmental impacts associated with hydrogen production via SOEC under different electricity pathways are mainly caused by the electricity supply, although manufacturing of SOEC plant significantly contributes to specific resource and environmental impact categories. For upstream impacts (CEENE and SED) electricity supply dominated fossil resource use across the life cycle, followed by nuclear. The manufacturing stage is responsible for 8 to $45 \%$ of total SED impacts, where the metal depletion and minerals are the main concern that can be associated with the manufacturing. The same applies to CEENE, however, the environmental impacts associated with SOEC manufacturing showed a minor contribution, inducing not more than $10 \%$ of total 
CEENE per $\mathrm{kg}$ of $\mathrm{H}_{2}$ produced. Compared with other energy and exergy-based indicators, SED

assigns higher impact factors to minerals and metals and smaller impact factors to fossil energy resources, land use, and nuclear energy (Rugani et al., 2011). In the manufacturing stage, the highest impact comes from stack because the lifetime is too short (five years considered in this study) and results in higher material expenditure and thereby resource depletion and environmental burdens. In the domain of Solid Oxide Electrolysis (SOE) and Solid Oxide Fuel Cells (SOFC) main impacts of manufacturing are due to industrial stack production (Lee et al., 2015; Rillo et al., 2017). Electricity, chromium, and steel are the most impacting inputs among all (Appendix A). Electricity and steel components are identified by many studies (Staffell et al., 2012; Häfele et al., 2016; Mehmeti et al., 2017) as the main important driver of the environmental burdens of the manufacturing phase. Thus, for emergy-oriented LCA indicators, the optimization of materials used in manufacturing is the key factor for improving the overall resource use efficiency, while the electricity input and its production chain can be seen as key factors for improving exergy-based LCA indicators because electricity accounts for nearly all the CEENE input.

For LCA-ReCiPe 2016 midpoint indicators, SOEC manufacturing has a high environmental impact, especially in terms of toxicity related indicators (marine, terrestrial and freshwater), mineral resource scarcity (SOP) and water consumption (WCP). Giraldi et al. (2015) highlighted that manufacturing of SOEC was particularly relevant for global warming, metal depletion, and ozone depletion impact categories. Manufacturing phase becomes more relevant when renewable energy sources are used. Given the short lifespan of a SOEC, the environmental burdens are large when amortized over the hydrogen produced throughout its lifetime. Hence, from an environmental perspective, emphasis should be on reducing degradation and expanding cell lifetime. Häfele et al. (2016) highlight that only improving cell performance could lower impacts already by 10 to $20 \%$. Further relative reductions of the overall environmental impact can be achieved in the manufacturing and disposal phases, by either reducing the energy inputs and waste streams of these processes or combining conventional energy sources with low environmental impact sources. Lee et 
al. (2015) demonstrating that using different electricity mixes in the modelling of manufacture of

SOFC systems (the same module is used also for SOEC) has substantial effects on the LCA results where impacts vary in the range from $32 \%$ to $170 \%$, depending on the energy mix used for electricity generation.

Still, for endpoint indicators, the main hotspot identified by contribution analysis for 5 out of 8 hydrogen production pathways (as illustrated in Appendix A) is the electricity supply. In hightemperature electrolysis with SOEC, a fraction of energy is supplied as heat, affecting global warming, photochemical oxidant formation (both human health and ecosystem) and damage to resource availability, since natural gas is used to provide process heat in the reference case. Hence, the electrolyzer operating mode (thermal-neutral to below thermal-neutral) will determine the magnitude of these environmental impacts, the efficiency of hydrogen production and system economic effects (Harvego et al., 2012). Shifting from combined natural gas and electric to an allelectric hydrogen production plant will be associated with the increased electricity usage which in turn should rely on clean energy sources to guarantee a good environmental performance.

\subsection{Comparison of environmental impact metrics}

A comparison of SOEC performance for midpoints and the three indicative endpoint indicators is presented in Figure 6. Hydrogen production has so far been dominated by fuel-based systems such as coal gasification (CG) or steam methane reforming (SMR). The GWP of SMR varies from 8.9 to $12.9 \mathrm{~kg} \mathrm{CO}-\mathrm{eq} / \mathrm{kg} \mathrm{H}$ (Spath and Mann, 2001; Cetinkaya et al., 2012b; Bhandari et al., 2014), which is still lower than SOEC under conventional energy supply $\left(25.64 \mathrm{~kg} \mathrm{CO}_{2}\right.$-eq/kg $\mathrm{H}_{2}$ from Italian grid). The GWP of CG hydrogen production is reported from 11.82 to $20.39 \mathrm{~kg} \mathrm{CO}$-eq/kg $\mathrm{H}_{2}$ (ANL, 2012; Cetinkaya et al., 2012). Susmozas et al. (2015) analyzed $\mathrm{H}_{2}$ production via steam reforming glycerol and bio-oil reporting a GWP of 12.65 and $3.79 \mathrm{~kg} \mathrm{CO}_{2}$-eq/kg $\mathrm{H}_{2}$, respectively. Environmental impacts from the non-fossil $\mathrm{H}_{2}$ pathways (i.e. biomass-based systems) tend to be lower than fossil-based systems. However, the impacts will depend on the type, quality, and origin 
of feedstock. The final results from different studies and the ranking of the methods are affected by assumptions regarding the technical aspects and the methodological decisions such as the difference in scope and the reliability of data sources (Valente et al., 2016).

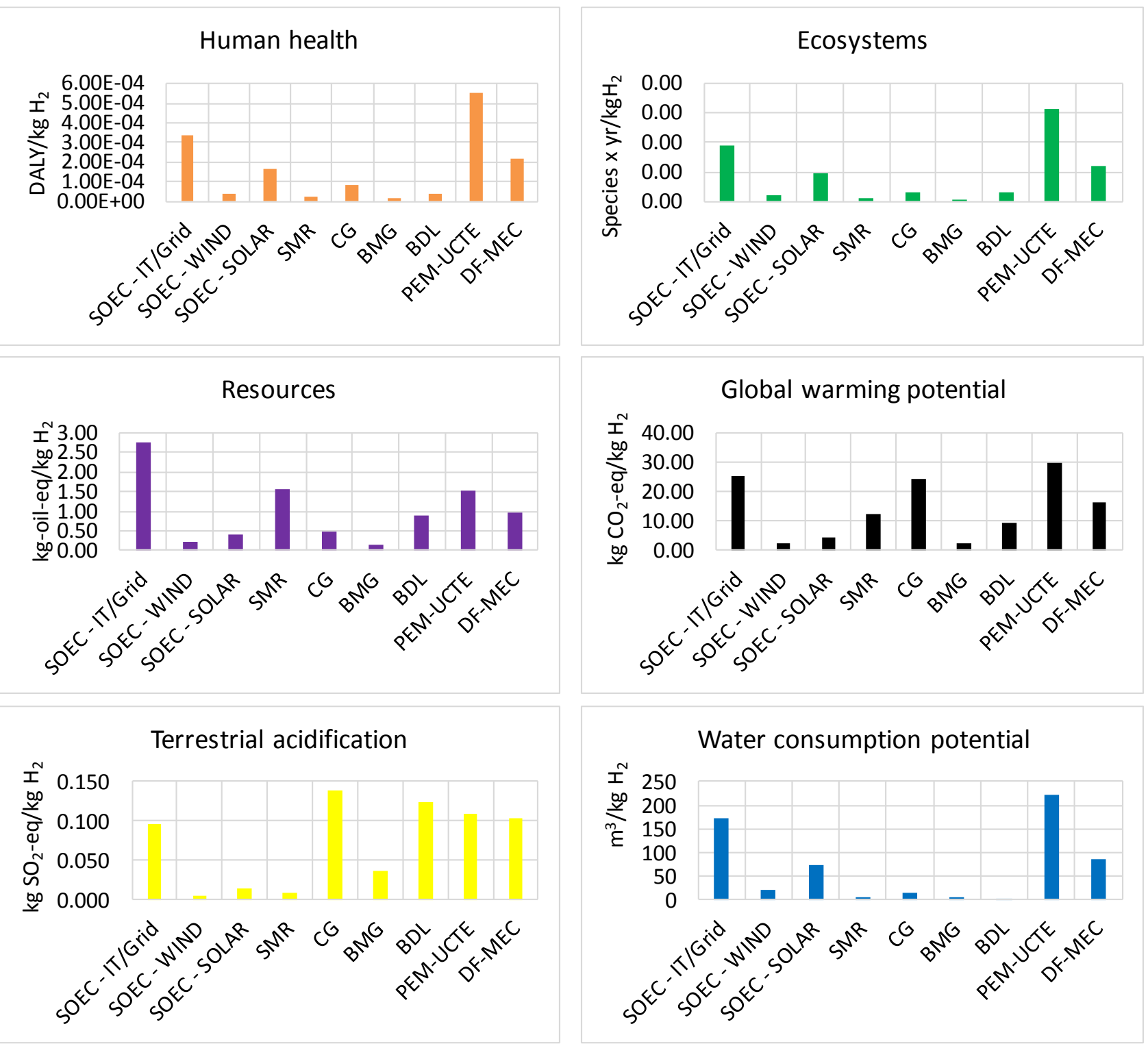

Figure 6. Comparison of SOEC performance with other hydrogen production methods. BMG: (Data for other technologies retrieved from Mehmeti et al. (2018)). SOEC: Solid oxide electrolysis cells; SMR: Steam methane reforming; CG: Coal gasification; Biomass Gasification; BDL: Biomass Reformation; E-PEM: Electrolysis with Proton exchange membrane (PEM): DF-MEC: Dark fermentation + microbial electrolysis cell (MEC) without energy recovery

It should be noted that there is no system that results in perfect environmental performance and the choice of a hydrogen production system will mainly depend on the local conditions and availability 
and type of energy sources. In fossil fuel-based systems, the environmental impacts associated with hydrogen production are due to the consumption of coal or natural gas as a feedstock, whereas electrolysis mainly limited to the electricity supply (Simons and Bauer, 2011; Bhandari et al., 2014; Mehmeti et al., 2018). Therefore, the source of electricity that makes up a country's grid mix (mainly in grid-based electrolysis) will determine the advantages and drawbacks of SOEC way with respect to its competitors. To study the performance of SOEC we further examined the LCA-based impacts of grid electricity $\mathrm{H}_{2}$ production in different European countries (Table 4). The life cycle environmental impacts of electrolytic hydrogen production show big differences between countries analyzed because of large differences in the power generation method used. For example, GWP range from $3.31 \mathrm{~kg} \mathrm{CO}_{2}$-eq/kg $\mathrm{H}_{2}$ in Norway mainly using hydro-power-plants to $48.24 \mathrm{~kg} \mathrm{CO}_{2^{-}}$ eq $/ \mathrm{kg} \mathrm{H}_{2}$ in Poland which uses coal as its main energy source. The ionizing radiation potential is the highest in France and Switzerland which have a great share of nuclear technology for electricity generation. The eutrophication potential is the highest in Germany while land use in Finland. In terms of damages to human health and ecosystem, the highest impacts are observed in Sweden due to highest the water consumption potential, while damages to resource availability in Nederland's and Poland due to highest demand for fossil resources (oil, coal, and gas). 


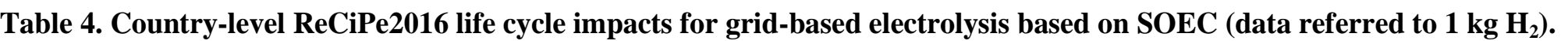

\begin{tabular}{|c|c|c|c|c|c|c|c|c|c|c|c|}
\hline Impact category & Unit & 胥 & 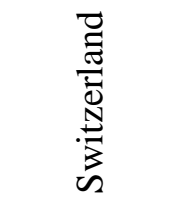 & 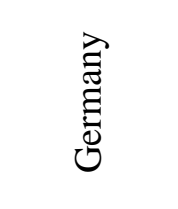 & 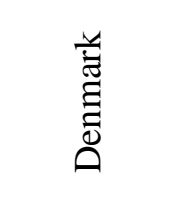 & 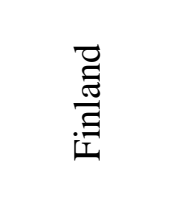 & 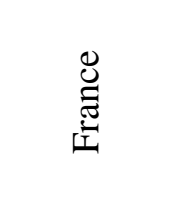 & 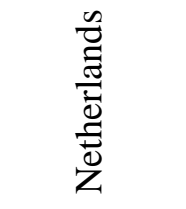 & $\begin{array}{l}\overrightarrow{\hat{n}} \\
\stackrel{0}{0} \\
\text { z }\end{array}$ & $\begin{array}{l}\overrightarrow{0} \\
\text { ज़ } \\
0\end{array}$ & 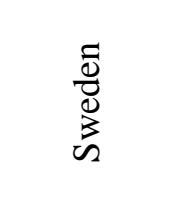 \\
\hline GWP & $\mathrm{kg} \mathrm{CO}_{2}$-eq & 25.64 & 7.18 & 28.85 & 25.81 & 20.51 & 5.66 & 29.62 & 3.31 & 48.24 & 5.44 \\
\hline ODP & kg CFC11-eq & $1.19 \times 10^{-5}$ & $4.77 \times 10^{-6}$ & $1.18 \times 10^{-5}$ & $1.39 \times 10^{-5}$ & $1.09 \times 10^{-5}$ & $3.93 \times 10^{-6}$ & $1.19 \times 10^{-5}$ & $3.57 \times 10^{-6}$ & $6.88 \times 10^{-6}$ & $5.06 \times 10^{-6}$ \\
\hline IRP & kBq Co60-eq & 3.92 & 24.97 & 12.53 & 3.18 & 12.19 & 38.60 & 4.40 & 2.37 & 1.28 & 21.73 \\
\hline HOFP & $\mathrm{kg} \mathrm{NO}_{\mathrm{x}}$-eq & 0.0501 & 0.011 & 0.025 & 0.030 & 0.032 & 0.012 & 0.037 & 0.004 & 0.074 & 0.011 \\
\hline PMFP & kg PM2.5-eq & 0.0256 & 0.0073 & 0.0092 & 0.0161 & 0.0215 & 0.0064 & 0.0082 & 0.0025 & 0.0673 & 0.0078 \\
\hline EOFP & $\mathrm{kg} \mathrm{NO}_{\mathrm{x}}$-eq & 0.0113 & 0.0256 & 0.0304 & 0.0328 & 0.0119 & 0.0377 & 0.0046 & 0.0749 & 0.07 & 0.0113 \\
\hline TAP & $\mathrm{kg} \mathrm{SO}_{2}$-eq & 0.0225 & 0.0321 & 0.0504 & 0.0475 & 0.0203 & 0.0333 & 0.0063 & 0.2200 & 0.22 & 0.0225 \\
\hline FEP & kg P-eq & 0.0049 & 0.0329 & 0.0072 & 0.0078 & 0.0022 & 0.0113 & 0.0008 & 0.0491 & 0.05 & 0.0049 \\
\hline TETP & kg 1.4DCB-eq & 0.0057 & 0.0052 & 0.0055 & 0.0065 & 0.0064 & 0.0046 & 0.0035 & 0.0094 & 0.00937 & 0.0057 \\
\hline FETP & kg 1.4DCB-eq & 0.214 & 0.18 & 0.84 & 0.27 & 0.28 & 0.13 & 0.35 & 0.06 & 1.39 & 0.11 \\
\hline METP & $\mathrm{kg} 1.4 \mathrm{DCB}-\mathrm{eq}$ & 0.32 & 0.26 & 1.16 & 0.39 & 0.41 & 0.19 & 0.52 & 0.09 & 1.92 & 0.17 \\
\hline HTPc & $\mathrm{kg}$ 1.4DCB-eq & 0.89 & 0.79 & 2.07 & 0.99 & 1.00 & 0.67 & 1.12 & 0.55 & 3.52 & 0.64 \\
\hline HTPnc & kg 1.4DCB-eq & 222.01 & 180.63 & 839.94 & 292.63 & 315.95 & 128.14 & 358.96 & 68.12 & 1316.50 & 127.20 \\
\hline LOP & $\mathrm{m}^{2} \times$ y crop-eq & 0.083 & 0.05 & 0.18 & 0.36 & 0.52 & 0.05 & 0.18 & 0.05 & 0.42 & 0.21 \\
\hline SOP & $\mathrm{kg} \mathrm{Cu}-\mathrm{eq}$ & 0.030 & 0.041 & 0.035 & 0.034 & 0.033 & 0.049 & 0.028 & 0.029 & 0.027 & 0.039 \\
\hline FFP & $\mathrm{kg}$ oil-eq & 7.59 & 2.04 & 7.16 & 6.94 & 5.30 & 1.55 & 9.04 & 0.97 & 11.87 & 1.47 \\
\hline WCP & $\mathrm{m}^{3}$ & 171.07 & 330.80 & 99.56 & 77.57 & 143.00 & 190.89 & 31.11 & 103.78 & 58.86 & 587.67 \\
\hline $\mathrm{HH}$ & DALY & $3.40 \times 10^{-4}$ & $7.44 \times 10^{-4}$ & $2.60 \times 10^{-4}$ & $2.06 \times 10^{-4}$ & $3.50 \times 10^{-4}$ & $4.30 \times 10^{-4}$ & $1.02 \times 10^{-4}$ & $2.31 \times 10^{-4}$ & $2.32 \times 10^{-4}$ & $1.31 \times 10^{-3}$ \\
\hline EQ & Species $\times y$ & $1.89 \times 10^{-6}$ & $4.46 \times 10^{-6}$ & $1.42 \times 10^{-6}$ & $1.11 \times 10^{-6}$ & $1.98 \times 10^{-6}$ & $2.57 \times 10^{-6}$ & $4.89 \times 10^{-7}$ & $1.38 \times 10^{-6}$ & $9.87 \times 10^{-7}$ & $7.92 \times 10^{-6}$ \\
\hline RA & $\$$ & 2.767 & 0.50 & 0.91 & 1.39 & 0.91 & 0.43 & 2.46 & 0.28 & 1.02 & 0.37 \\
\hline
\end{tabular}


The LCA results in this study suggest that a high share of wind energy, solar energy, and

hydropower would lead to lower environmental impacts than a system with a high share of fossilbased energy. This confirms the key finding of other studies (e.g. Cetinkaya et al., 2012a; Acar and Dincer, 2014; Bhandari et al., 2014) that using wind-turbine or solar-generated electricity to electrolyze water has arguably a large potential for producing $\mathrm{H}_{2}$ with little pollution. As shown, in the case of hydropower electricity pathway, the contribution of freshwater depletion is critical, although it is the route which exhibited the lowest resource scarcity rate. Still, due to intermittent nature of renewable power system, battery banks or electricity purchased from the grid become necessary for a 24/7 operation of SOECs, hence increasing the overall environmental impact of the hydrogen produced. On the other hand, there is a fundamental attractiveness about implementing such a technology that will allow the broad penetration of renewable electricity $\left(\mathrm{H}_{2}\right.$ via electrolysis could be done as and when surplus capacity exists within the electricity network) into the European energy system to provide an uninterrupted supply of electricity. Using excess grid energy or curtailed power generated by renewable energy systems to produce hydrogen that can be used as a fuel in fuel cell mode or stored for a later time is an attractive solution for such technologies. In such a case material problems due to load changes must be solved to fit with intermittent renewable energy generated electricity (Bhandari et al., 2014). The low electricity demand is the most significant advantage of SOEC systems in respect to other electrolytic technologies. System power consumption of hydrogen generation via SOEC requires $41.2 \mathrm{kWh} / \mathrm{kgH}_{2}$ (Sunfire, 2016), compared to $50-91.2 \mathrm{kWh} / \mathrm{kgH}_{2}$ and $50-83.4 \mathrm{kWh} / \mathrm{kgH}_{2}$ reported for alkaline electrolysis and polymer electrolyte membranes electrolysis (Götz et al., 2016), respectively, leading to a minimum of about $9 \mathrm{kWh}$. Based on the typical impacts of the Italian grid mix, a reduction of $18 \%$ in the GWP impacts could be achieved for $1 \mathrm{kgH}_{2}$ produced.

As a final note, it is clear that the environmental performance of hydrogen production will depend on the life cycle inventory and the impact assessment method, production option (central in large plants or forecourt in distributed production facilities), size, availability of renewable energy at the 
local scale (solar and wind energy) and lifetime endurance of components. The interest recently

shifted from centralized production to distributed generation, to be compatible with forecourt plant designs, whereas large-scale hydrogen production will continue to be based on conventional fuels, preferred from the economic point of view. In any case, because of their larger size and associated economies of scale, larger systems will perform better than smaller systems both from an environmental and an economic point of view. Electrolytic methods are found to be less attractive when production costs are considered (Acar and Dincer, 2014), thus, a comprehensive framework for assessing economic, social and environmental aspects of hydrogen energy systems are needed to facilitate decision-making in the hydrogen energy sector.

\section{Conclusions}

A spectrum of life cycle impact methods capturing both upstream and downstream life-cycle activities was used to provide a reference for the environmental impacts of hydrogen production through high-temperature electrolysis via Solid Oxide Electrolysis Cell (SOEC) technology. The study reported life-cycle performance using eight different electricity sources, starting with the evaluation of resource consumption, using thermodynamic-based resource accounting methods, and the environmental performance of emissions and resource extraction using midpoint (problemoriented) and endpoint (damage-oriented) indicators, estimated with LCA-ReCiPe 2016. From a life-cycle perspective, the environmental and energy performance of hydrogen via SOEC is highly dependent on the operation stage, i.e. on the electricity supply source. The quantified results show that there is no "optimal 'electricity source for all environmental impacts and that the renewable oriented energy mix, providing electricity to the water electrolyzer, is crucial to secure an environmental advantage versus competitors. Along with resource conservation, hydrogen from renewable power demonstrates its potential to mitigate life-cycle emissions by capping/interrupting the fluctuating renewable electricity. Nevertheless, it should be noted that the ranking of electricity pathways strongly depends on the assumptions made in each study and several issues such intermittency or the LCA approach chosen (midpoint vs. endpoint) need to be considered when 
drawing final conclusions. The results of the LCA methods separately might be contradictory; hence, a better-informed overview could be provided to the decision makers by using a systematic combining approach.

The results accentuate that, apart from global warming, use of water consumption as an indicator is of a paramount importance for improved decision-making processes towards exploring additional valuable insights, especially for local or regional hydrogen projects. In the manufacturing stage, penalties arise in environmental impacts such as toxicity, eutrophication, and metal resource depletion. The short lifetime of stack raises the energy usage and equipment environmental cost considerably and makes it the most important contribution to the overall manufacturing impact. Hence, the environmental performance of SOEC is reduced by increasing the energy efficiency and ratios of upstream processes in the production chain. In this context, also research and technological efforts are mainly required towards improved efficiency, durability and minimum environmental adverse effects in manufacturing. Our assessment is affected by great uncertainty in the manufacturing stage; hence, more detailed data collection, with focus on obtaining information from manufacturers and facilities, will significantly increase the representativeness and the accuracy of the final results.

This work contributed to a widening of environmental assessment methodology progressing beyond the state-of-the-art, thereby making it more useful in guiding strategic technology choices and providing the scientific and industrial community with a reference on environmental sustainability aspects of Solid Oxide Electrolysis Cells (SOEC). In the future studies, the system boundaries of ecological life cycle assessment should be extended, capturing all stages (from cradle-to-grave) which include the use of hydrogen produced, as well as capturing dynamics of renewable power generation systems and the lifetime of SOEC systems under different conditions. Moreover, future research should be oriented towards life cycle sustainability assessment by taking into account the full spectrum of impacts (environmental, economic, and social) to clarify the trade-offs between the three sustainability pillars. 


\section{Acknowledgments}

We thank Professor Sergio Ulgiati for his helpful review, insightful comments and suggestions. The author Andi Mehmeti want to thank the School of Applied Sciences at the University of Huddersfield for hosting him as a visiting researcher.

Funding: This work is supported by the European Commission through Project nr. 731224- H2020LCE-2016-ERA "Increasing penetration of renewable power, alternative fuels and grid flexibility by cross-vector electrochemical processes" (BALANCE).

\section{References}

Acar, C., Dincer, I., 2014. Comparative assessment of hydrogen production methods from renewable and non-renewable sources. Int. J. Hydrogen Energy. doi:10.1016/j.ijhydene.2013.10.060

ANL, 2012. GREET Model [WWW Document]. Argonne Natl. Lab. URL http://greet.es.anl.gov/

Arbault, D., Rugani, B., Marvuglia, A., Benetto, E., Tiruta-Barna, L., 2014. Emergy evaluation using the calculation software SCALE: Case study, added value and potential improvements. Sci. Total Environ. 472, 608-619. doi:10.1016/j.scitotenv.2013.11.087

Ball, M., Weeda, M., 2015. The hydrogen economy - Vision or reality? Int. J. Hydrogen Energy 40, 7903-7919. doi:10.1016/j.ijhydene.2015.04.032

Bare, J.C., Hofstetter, P., Pennington, D.W., Udo de Haes, H.A., 2000. Life cycle impact assessment workshop summary. Midpoints versus endpoints: The sacrifices and benefits. Int. J. Life Cycle Assess. 5, 319-326. doi:10.1053/jhep.2001.21045

Bhandari, R., Trudewind, C.A., Zapp, P., 2014. Life cycle assessment of hydrogen production via electrolysis - A review. J. Clean. Prod. doi:10.1016/j.jclepro.2013.07.048

Brown, M.T., Ulgiati, S., 2004. Energy quality, emergy, and transformity: H.T. Odum's contributions to quantifying and understanding systems. Ecol. Modell. doi:10.1016/j.ecolmodel.2004.03.002

Brown, M.T., Ulgiati, S., 2002. Emergy evaluations and environmental loading of electricity production systems. J. Clean. Prod. 10, 321-334. doi:10.1016/S0959-6526(01)00043-9

Buonocore, E., Vanoli, L., Carotenuto, A., Ulgiati, S., 2015. Integrating life cycle assessment and emergy synthesis for the evaluation of a dry steam geothermal power plant in Italy. Energy 86, 476-487. doi:10.1016/j.energy.2015.04.048

Cetinkaya, E., Dincer, I., Naterer, G.F., 2012. Life cycle assessment of various hydrogen production methods. Int. J. Hydrogen Energy 37, 2071-2080. doi:10.1016/j.ijhydene.2011.10.064

Dewulf, J., Bösch, M.E., De Meester, B., Van Der Vorst, G., Van Langenhove, H., Hellweg, S., Huijbregts, M.A.J., 2007. Cumulative exergy extraction from the natural environment (CEENE): A comprehensive life cycle impact assessment method for resource accounting. Environ. Sci. Technol. 41, 8477-8483. doi:10.1021/es0711415

Dincer, I., Acar, C., 2014. Review and evaluation of hydrogen production methods for better sustainability. Int. J. Hydrogen Energy 40, 11094-11111. doi:10.1016/j.ijhydene.2014.12.035

Dong, Y.H., Ng, S.T., 2014. Comparing the midpoint and endpoint approaches based on ReCiPe-a study of commercial buildings in Hong Kong. Int. J. Life Cycle Assess. 19, 1409-1423. doi:10.1007/s11367-014-0743-0

Ehtiwesh, I.A.S., Coelho, M.C., Sousa, A.C.M., 2016. Exergetic and environmental life cycle assessment analysis of concentrated solar power plants. Renew. Sustain. Energy Rev. 56, 145155. doi:10.1016/j.rser.2015.11.066

Fischer, M., Fltenbacher, Schuller, 2005. ECTOS report 16. Life cycle impact assessment. Energy 125. 
Gahleitner, G., 2013. Hydrogen from renewable electricity: An international review of power-to-gas pilot plants for stationary applications. Int. J. Hydrogen Energy.

Gerboni, R., Pehnt, M., Viebahn, P., Lavagno, E., 2008. Final report on technical data , costs and life cycle inventories of fuel cells. New Energy Externalities Dev. Sustain. (NEEDS). 1-75.

Giraldi, M.R., François, J.-L., Martin-del-Campo, C., 2015. Life cycle assessment of hydrogen production from a high temperature electrolysis process coupled to a high temperature gas nuclear reactor. Int. J. Hydrogen Energy 40, 4019-4033. doi:10.1016/j.ijhydene.2015.01.093

Goedkoop, M., Heijungs, R., De Schryver, A., Struijs, J., van Zelm, R., 2013. ReCiPe 2008. A LCIA method which comprises harmonised category indicators at the midpoint and the endpoint level. Characterisation.

Götz, M., Lefebvre, J., Mörs, F., McDaniel Koch, A., Graf, F., Bajohr, S., Reimert, R., Kolb, T., 2016. Renewable Power-to-Gas: A technological and economic review. Renew. Energy. doi:10.1016/j.renene.2015.07.066

Granovskii, M., Dincer, I., Rosen, M.A., 2006. Life cycle assessment of hydrogen fuel cell and gasoline vehicles. Int. J. Hydrogen Energy 31, 337-352. doi:10.1016/j.ijhydene.2005.10.004

Graziadio, M., Conti, B., Giannini, A., Munoz, C.B., McPhail, S.J., Carlini, M., 2016. An analysis of the effects of test bench architecture on solid oxide fuel cell and electrolysis characterization and the role of international standards, in: ECS Transactions. doi:10.1149/07537.0015ecst

Häfele, S., Hauck, M., Dailly, J., 2016. Life cycle assessment of the manufacture and operation of solid oxide electrolyser components and stacks. Int. J. Hydrogen Energy 41, 13786-13796. doi:10.1016/j.ijhydene.2016.05.069

Hanafi, J., Riman, A., 2015. Life Cycle Assessment of a Mini Hydro Power Plant in Indonesia: A Case Study in Karai River. Procedia CIRP 29, 444-449. doi:10.1016/j.procir.2015.02.160

Harvego, E.A., O’Brien, J.E., McKellar, M.G., 2012. System evaluation and life-cycle cost analysis of a commercialscale high-temperature electrolysis hydrogen production plant. ASME 2012 Int. Mech. Eng. Congr. Expo. IMECE 2012 6, 875-884. doi:10.1115/IMECE2012-89649

Hernandez, M., Messagie, M., De Gennaro, M., Van Mierlo, J., 2017. Resource depletion in an electric vehicle powertrain using different LCA impact methods. Resour. Conserv. Recycl. 120, 119-130. doi:10.1016/j.resconrec.2016.11.005

Hertwich, E.G., 2013. Addressing biogenic greenhouse gas emissions from hydropower in LCA. Environ. Sci. Technol. 47, 9604-9611. doi:10.1021/es401820p

Hertwich, E.G., Gibon, T., Bouman, E.A., Arvesen, A., Suh, S., Heath, G.A., Bergesen, J.D., Ramirez, A., Vega, M.I., Shi, L., 2015. Integrated life-cycle assessment of electricity-supply scenarios confirms global environmental benefit of low-carbon technologies. Proc. Natl. Acad. Sci. 112, 6277-6282. doi:10.1073/pnas.1312753111

Huijbregts, M.A.J., Steinmann, Z.J.N., Elshout, P.M.F., Stam, G., Verones, F., Vieira, M., Zijp, M., Hollander, A., van Zelm, R., 2017. ReCiPe2016: A harmonised life cycle impact assessment method at midpoint and endpoint level. Int. J. Life Cycle Assess. 22, 138-147. doi:10.1007/s11367-016-1246-y

Huijbregts, M. a. J., Steinmann, Z.J.. ., Elshout, P.M.F., Stam, G., Verones, F., Vieira, M.D.M., Zijp, M., van Zelm, R., 2016. ReCiPe 2016: A harmonized life cycle impact assessment method at midpoint and enpoint level - Report 1 : Characterization 194.

Huysman, S., Schaubroeck, T., Dewulf, J., 2015. Exergy and Cumulative Exergy Use Analysis. Sustain. Assess. Renewables-Based Prod. Methods Case Stud. 141.

IAEA, 2013. Hydrogen Production Using Nuclear Energy 400.

Ingwersen, W.W., 2011. Emergy as a Life Cycle Impact Assessment Indicator. J. Ind. Ecol. 15, 550-567. doi:10.1111/j.1530-9290.2011.00333.x

Koroneos, C., Dompros, A., Roumbas, G., Moussiopoulos, N., 2004. Life cycle assessment of hydrogen fuel production processes. Int. J. Hydrogen Energy 29, 1443-1450. doi:10.1016/j.ijhydene.2004.01.016 
Laguna-Bercero, M.A., 2012. Recent advances in high temperature electrolysis using solid oxide fuel cells: A review. J. Power Sources 203, 4-16. doi:10.1016/j.jpowsour.2011.12.019

Lee, Y.D., Ahn, K.Y., Morosuk, T., Tsatsaronis, G., 2015. Environmental impact assessment of a solid-oxide fuel-cell-based combined-heat-and-power-generation system. Energy 79, 455-466.

Liao, W., Heijungs, R., Huppes, G., 2012. Thermodynamic resource indicators in LCA: A case study on the titania produced in Panzhihua city, southwest China. Int. J. Life Cycle Assess. 17, 951-961. doi:10.1007/s11367-012-0429-4

Marban, G., Valdes-Soleis, T., 2007. Towards the hydrogen economy? Int. J. Hydrogen Energy 32, 1625-1637. doi:10.1016/j.ijhydene.2006.12.017

Masoni, P., Zamagni, A., 2011. Guidance Document for performing LCAs on Fuel Cells and Hydrogen Technologies (FC-HyGuide). Project deliverable for Fuel cell and Hydrogen-Joint Undertaking.

Mehmeti, A., Angelis-Dimakis, A., Arampatzis, G., McPhail, S.J., Ulgiati, S., 2018a. Life Cycle Assessment and Water Footprint of Hydrogen Production Methods: From Conventional to Emerging Technologies. Environments. doi:10.3390/environments5020024

Mehmeti, A., McPhail, S., Pumiglia, D., Carlini, M., 2016a. Life cycle sustainability of solid oxide fuel cells: From methodological aspects to system implications. J. Power Sources. doi:10.1016/j.jpowsour.2016.06.078

Mehmeti, A., McPhail, S., Ulgiati, S., 2018b. Life cycle inventory data and metrics for hightemperature fuel cells: A streamlined decision-support tool and case study application. Energy. doi:10.1016/j.energy.2018.06.139

Mehmeti, A., Munoz, C.B., McPhail, S.J., 2017. Emergy resource-based life cycle analysis of solidoxide fuel-cell power systems.

Mehmeti, A., Pedro Pérez-Trujillo, J., Elizalde-Blancas, F., Angelis-Dimakis, A., McPhail, S.J., 2018c. Exergetic, environmental and economic sustainability assessment of stationary Molten Carbonate Fuel Cells. Energy Convers. Manag. 168. doi:10.1016/j.enconman.2018.04.095

Mehmeti, A., Santoni, F., Della Pietra, M., McPhail, S.J., 2016b. Life cycle assessment of molten carbonate fuel cells: State of the art and strategies for the future. J. Power Sources 308. doi:10.1016/j.jpowsour.2015.12.023

Minh, N.Q., Mogensen, M.B., 2013. Reversible Solid Oxide Fuel Cell Technology for Green Fuel and Power Production. Interface 22, 55-62. doi:10.1039/b105764m

Odum, H.T., 1996. Environmental accounting: EMERGY and environmental decision making, The International Journal of Life Cycle Assessment.

Patyk, A., Bachmann, T.M., Brisse, A., 2013. Life cycle assessment of H2 generation with high temperature electrolysis. Int. J. Hydrogen Energy 38, 3865-3880. doi:10.1016/j.ijhydene.2013.01.063

Primas, A., 2007. Life Cycle Inventories of new CHP systems. ecoinvent report No. 20. Ecoinvent 0.

Rillo, E., Gandiglio, M., Lanzini, A., Bobba, S., Santarelli, M., Blengini, G., 2017. Life Cycle Assessment (LCA) of biogas-fed Solid Oxide Fuel Cell (SOFC) plant. Energy 126, 585-602. doi:10.1016/j.energy.2017.03.041

Rørbech, J.T., Vadenbo, C., Hellweg, S., Astrup, T.F., 2014. Impact assessment of abiotic resources in LCA: Quantitative comparison of selected characterization models. Environ. Sci. Technol. 48, 11072-11081. doi:10.1021/es5023976

Rugani, B., Huijbregts, M.A.J., Mutel, C., Bastianoni, S., Hellweg, S., 2011. Solar energy demand (SED) of commodity life cycles. Environ. Sci. Technol. 45, 5426-5433. doi:10.1021/es103537f

Ruzzenenti, F., Bravi, M., Tempesti, D., Salvatici, E., Manfrida, G., Basosi, R., 2014. Evaluation of the environmental sustainability of a micro CHP system fueled by low-temperature geothermal and solar energy. Energy Convers. Manag. 78, 611-616. doi:10.1016/j.enconman.2013.11.025 Sala, S., Benini, L., Castellani, V., Vidal-Legaz, B., Pant, R., 2016. Environmental Footprint - 
Update of Life Cycle Impact Assessment methods ; DRAFT for TAB ( status : May 2, 2016 ) Resources, water, land 1-114.

Sciubba, E., Ulgiati, S., 2005. Emergy and exergy analyses: Complementary methods or irreducible ideological options? Energy. doi:10.1016/j.energy.2004.08.003

Simons, A., Bauer, C., 2011. Life cycle assessment of hydrogen production, Transition to hydrogen: pathways toward clean transportation. doi:10.1017/CBO9781139018036.006

Song, Q., Wang, Z., Li, J., 2013. Sustainability evaluation of e-waste treatment based on emergy analysis and the LCA method: A case study of a trial project in Macau. Ecol. Indic. 30, 138147. doi:10.1016/j.ecolind.2013.02.016

Spath, P.L., Mann, M.K., 2001. Life Cycle Assessment of Hydrogen Production via Natural Gas Steam Reforming. Energy NREL/TP-570-27637.

Staffell, I., Ingram, A., Kendall, K., 2012. Energy and carbon payback times for solid oxide fuel cell based domestic CHP. Int. J. Hydrogen Energy 37, 2509-2523. doi:10.1016/j.ijhydene.2011.10.060

Steinhurst, W., Knight, P., Schultz, M., 2012. Hydropower Greenhouse Gas Emissions 1-23.

Sunfire, 2016. Highly Efficient and Low-Cost Hydrogen Production Steam-Electrolyser Highly Efficient and Low-Cost Hydrogen Production. http//www.sunfire.de/en/productstechnology/hydrogen-generator (accessed Oct 2017) 5-6.

Susmozas, A., Iribarren, D., Dufour, J., 2015. Assessing the Life-Cycle Performance of Hydrogen Production via Biofuel Reforming in Europe. Resources 4, 398-411. doi: 10.3390/resources4020398

Taelman, S.E., De Meester, S., Schaubroeck, T., Sakshaug, E., Alvarenga, R.A.F., Dewulf, J., 2014. Accounting for the occupation of the marine environment as a natural resource in life cycle assessment: An exergy based approach. Resour. Conserv. Recycl. 91, 1-10. doi:10.1016/j.resconrec.2014.07.009

Turner, J.A., 2004. Sustainable Hydrogen Production. Science (80-. ). 305, 972-974. doi:10.1126/science.1103197

Ulgiati, S., Raugei, M., Bargigli, S., 2006. Overcoming the inadequacy of single-criterion approaches to Life Cycle Assessment. Ecol. Modell. 190, 432-442. doi:10.1016/j.ecolmodel.2005.03.022

Utgikar, V., Thiesen, T., 2006. Life cycle assessment of high temperature electrolysis for hydrogen production via nuclear energy. Int. J. Hydrogen Energy 31, 939-944. doi:10.1016/j.ijhydene.2005.07.001

Valderrama, C., 2016. High-Temperature Electrolysis. Encycl. Membr. 0, 2-4. doi:10.1007/978-3662-44324-8

Valente, A., Iribarren, D., Dufour, J., 2016. Life cycle assessment of hydrogen energy systems: a review of methodological choices. Int. J. Life Cycle Assess. 1-18. doi:10.1007/s11367-016$1156-\mathrm{z}$

Varun, Bhat, I.K., Prakash, R., 2009. LCA of renewable energy for electricity generation systems-A review. Renew. Sustain. Energy Rev. doi:10.1016/j.rser.2008.08.004

Viebahn, P., Soukup, O., Samadi, S., Teubler, J., Wiesen, K., Ritthoff, M., 2015. Assessing the need for critical minerals to shift the German energy system towards a high proportion of renewables. Renew. Sustain. Energy Rev. doi:10.1016/j.rser.2015.04.070

Wilfart, A., Prudhomme, J., Blancheton, J.P., Aubin, J., 2013. LCA and emergy accounting of aquaculture systems: Towards ecological intensification. J. Environ. Manage. 121, 96-109. doi:10.1016/j.jenvman.2013.01.031 


\section{Cover letter}

$[14 / 07 / 2018]$

Dear Esteemed Editor, Dear Esteemed Professor Klemeš, Dear Esteemed Professor Urbaniec as handling editor,

We wish to express our thanks to the reviewers, especially Reviewer No 1 for the very thorough and extensive review of the paper. We greatly appreciate also your help concerning improvement to this paper.

This manuscript has been fully corrected. We have studied the comments carefully and have made the correction which we hope to meet with your and their approval. Although reviewer does not consider important or highly uncertain to measure the endpoint indicators, we consider it essential for scenario evaluations and interpretations of LCA results. The main message we want to transmit is that LCA studies and future research direction should move from single indicators toward multi-criteria to explore additional insights.

In this revised, we improved the data quality to some extent by consulting the inventory with engineers and performing a systemic literature revision of previous studies on SOFC technology. This strengthened our manuscript and allowed us to make a greater theoretical and practical contribution.

Based on project partners request we updated the manuscript to include also the effects of electricity mix in different European countries on LCA-based impacts of $\mathrm{H}_{2}$ production in order to map effects (please see section 3.6). We believe the additional analyses discussed above have helped us to add value to our manuscript.

We have also try to do our best, and English writing has already been further polished in the newly revised manuscript by one co-author. As a result, we feel this version reads more cohesively and fluidly.

We look forward to hearing from you in due course,

Sincerely,

On behalf of co-authors,

ANDI MEHMETI I Ph.D.

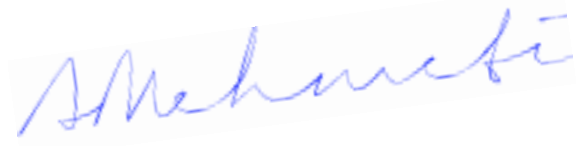




\section{Highlights:}

- A resource-based impact assessment using thermodynamic indicators was performed.

- It was complemented by a midpoint and endpoint life cycle impact assessment.

- Electricity supply dominates the result from different life-cycle stages.

- Sustainable hydrogen production is achieved with renewable electricity supply.

- Water use and global warming dominate the impacts on human health and ecosystems. 


\section{Figure Caption list:}

Figure 1. Schematic representation of the adopted conceptual framework for environmental sustainability assessment.

Figure 2. The configuration and operating principle of the SOEC unit (redrawn from (Minh and Mogensen (2013)).

Figure 3. System boundary and process flows of HTE-SOEC hydrogen production system. RR: renewable resources; NRR: non-renewable resources; FC: Fuel Cell; SOEC: Solid Oxide Electrolysis Cell (Modified from (Mehmeti et al., 2018b).

Figure 4. Relative contribution of each resource group to solar energy demand (SED) per $1 \mathrm{~kg} \mathrm{H}_{2}$ under different electricity pathways.

Figure 5. Relative contribution of each resource group to cumulative exergy extracted from the natural environment (CEENE) per $1 \mathrm{~kg} \mathrm{H}_{2}$ under different electricity pathways.

Figure 6. Comparison of SOEC performance with other hydrogen production methods (Data for other technologies retrieved from Mehmeti et al. (2018)). SOEC: Solid oxide electrolysis cells; SMR: Steam methane reforming; CG: Coal gasification; Biomass Gasification; BDL: Biomass Reformation; E-PEM: Electrolysis with Proton exchange membrane (PEM): DF-MEC: Dark fermentation + microbial electrolysis cell (MEC) without energy recovery 


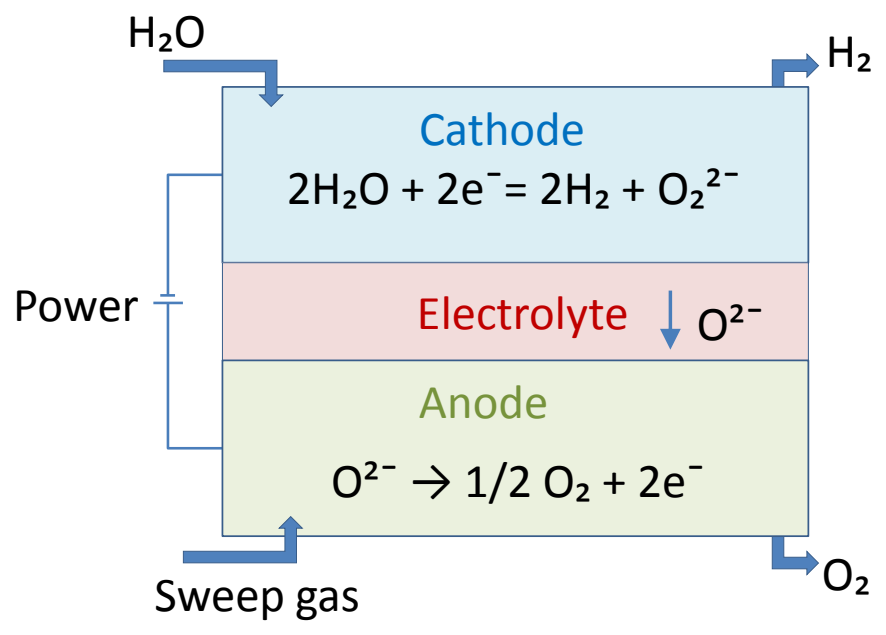



processes

Solar, Geothermal, Gravitational energy

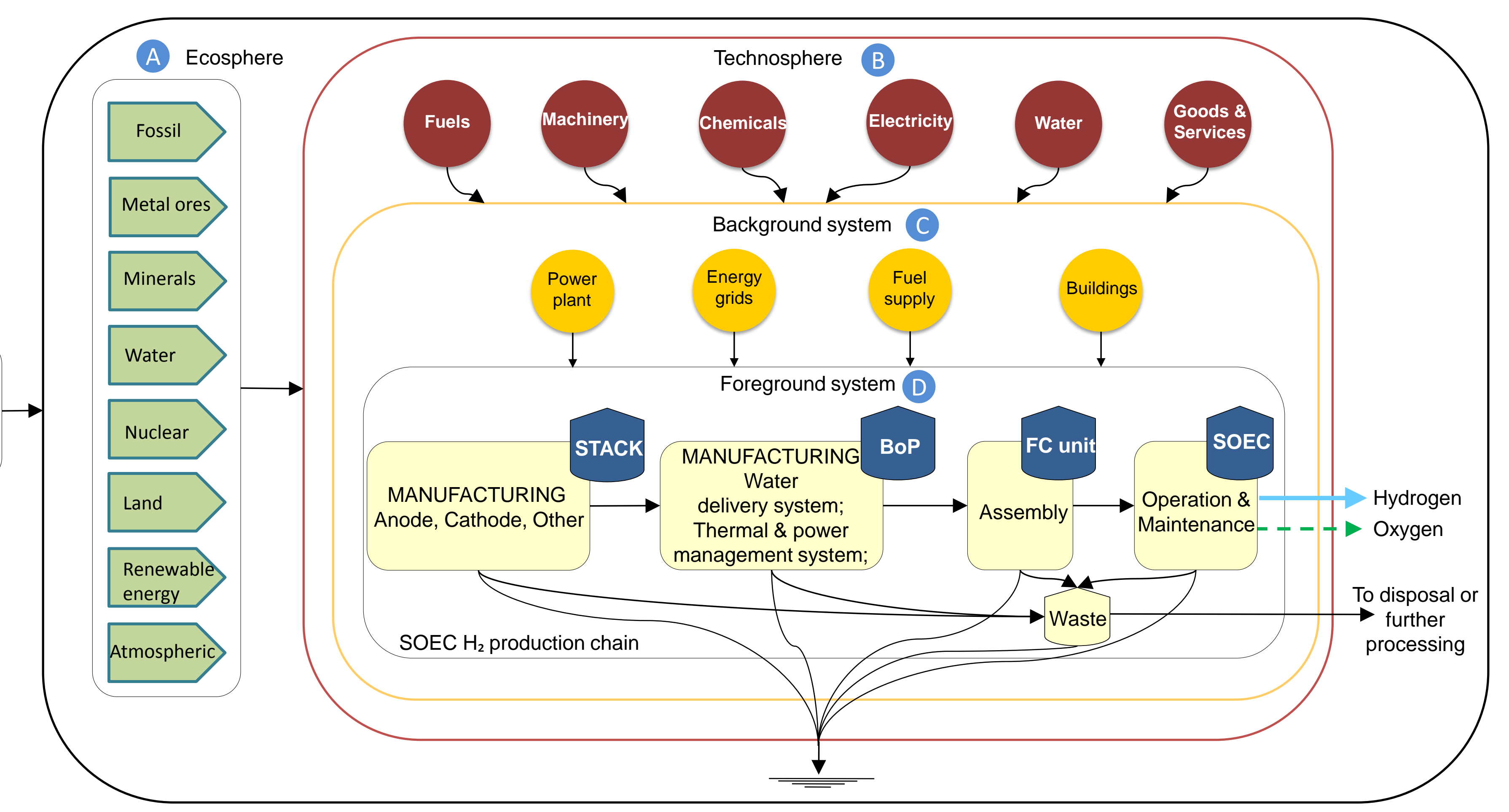



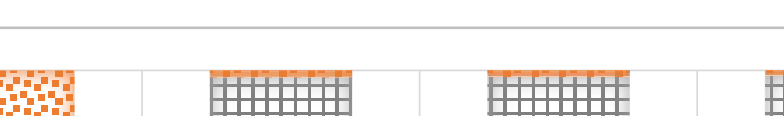

$80 \%$

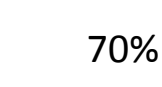

\begin{tabular}{l|l}
$\sum_{\text {岀 }}$ & $60 \%$ \\
১0 & $50 \%$
\end{tabular}

$40 \%$

$30 \%$

$20 \%$

$10 \%$

$0 \%$
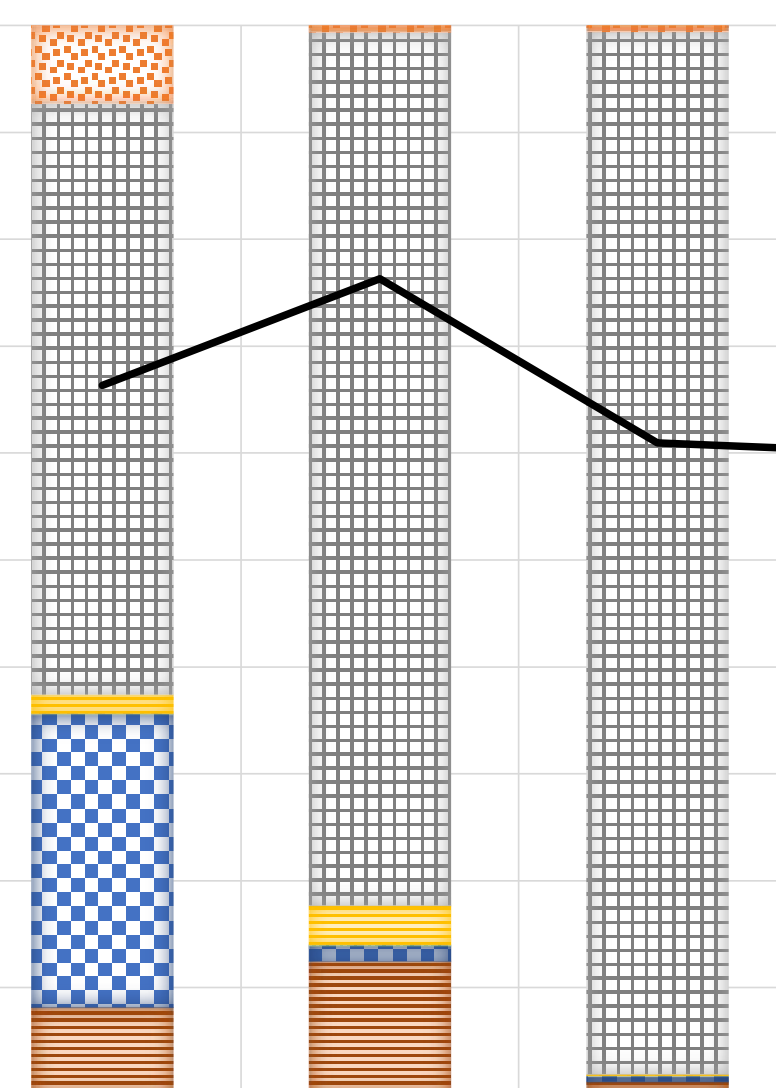

\&gas.

\begin{tabular}{|l}
\hline \hline Atmos. \&gas. \\
Renewable
\end{tabular}

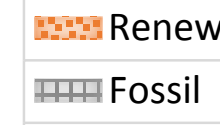

GRID

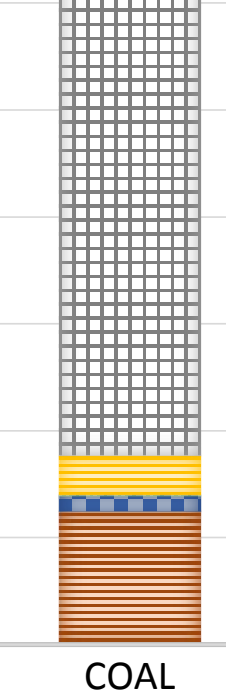

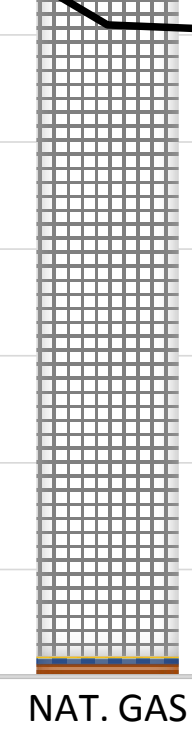
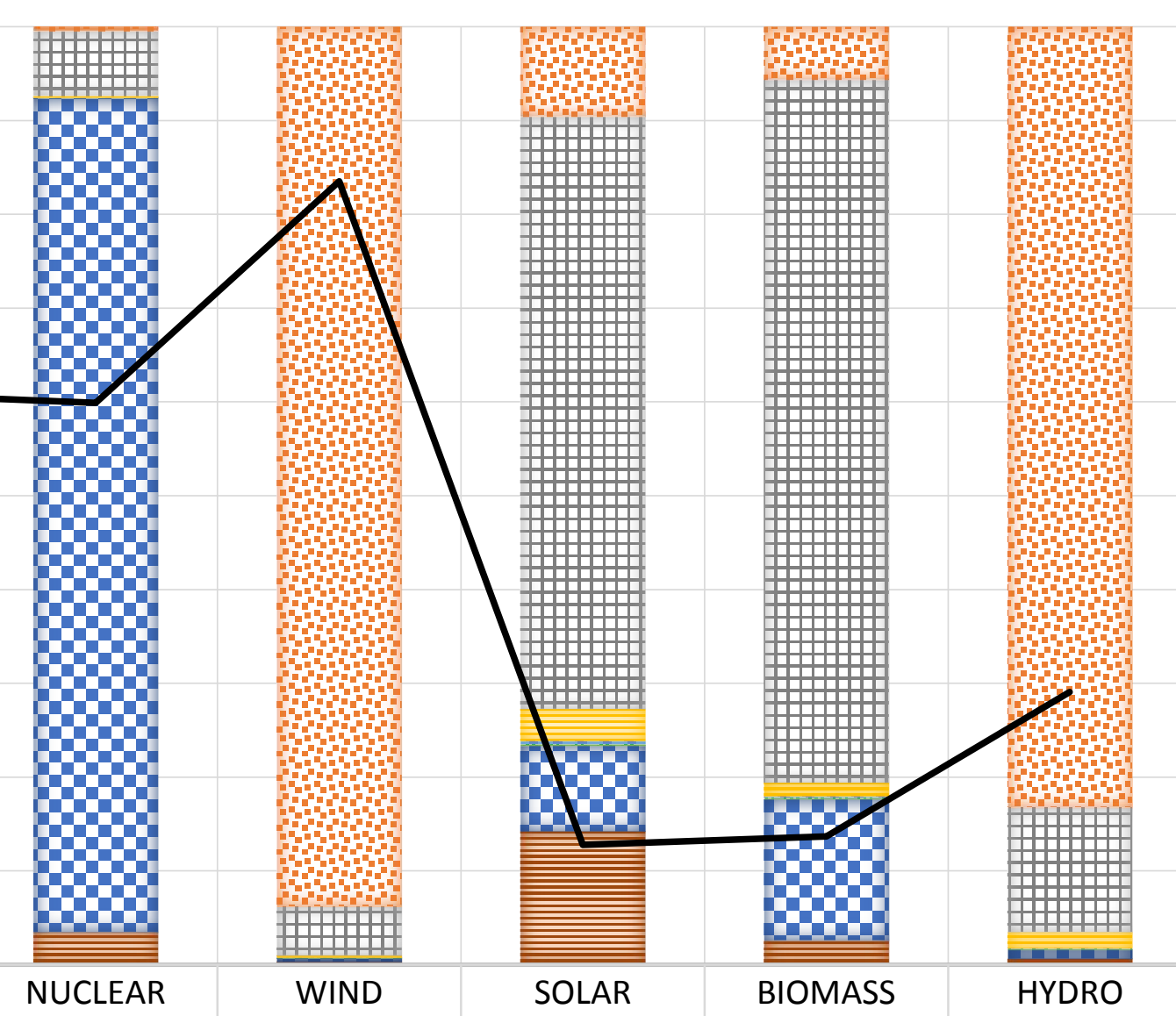

700.00

600.00

500.00

400.00

300.00

200.00

100.00

0.00

6.19

193.49

38.90

3.91

2.89

2.25

626.34

33.22

35.08

9.83

81.98

30.93

9.51

22.70

0.67

0.86

1.34

0.10

0.19

3.51

1.60

4.02

0.35

0.17

0.12

0.08

0.12

0.16

0.04

0.05

0.14

0.15

2.58

426.06

2.85

9.36

16.50

2.32

43.25

76.27

5.90

16.74

2.24

14.56

2.88

1.56

530.79

610.54

487.71

479.25

668.09

102.35

109.42

232.56 
Human health

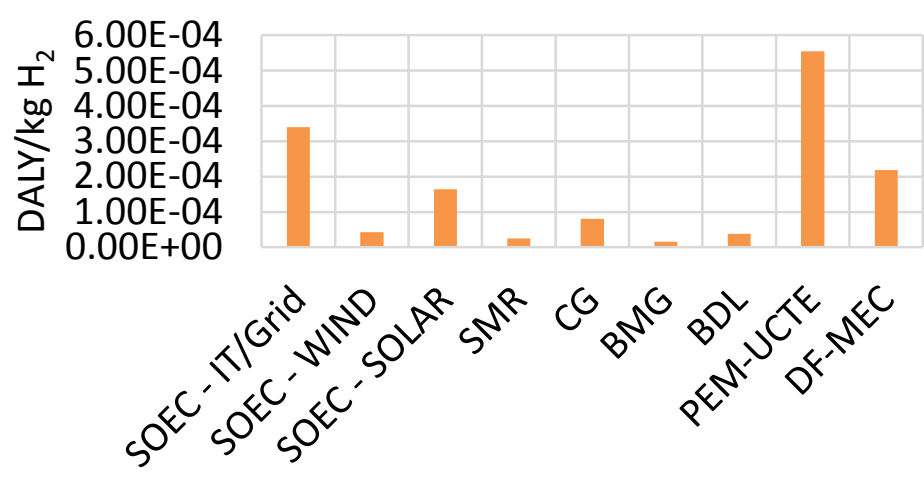

Resources
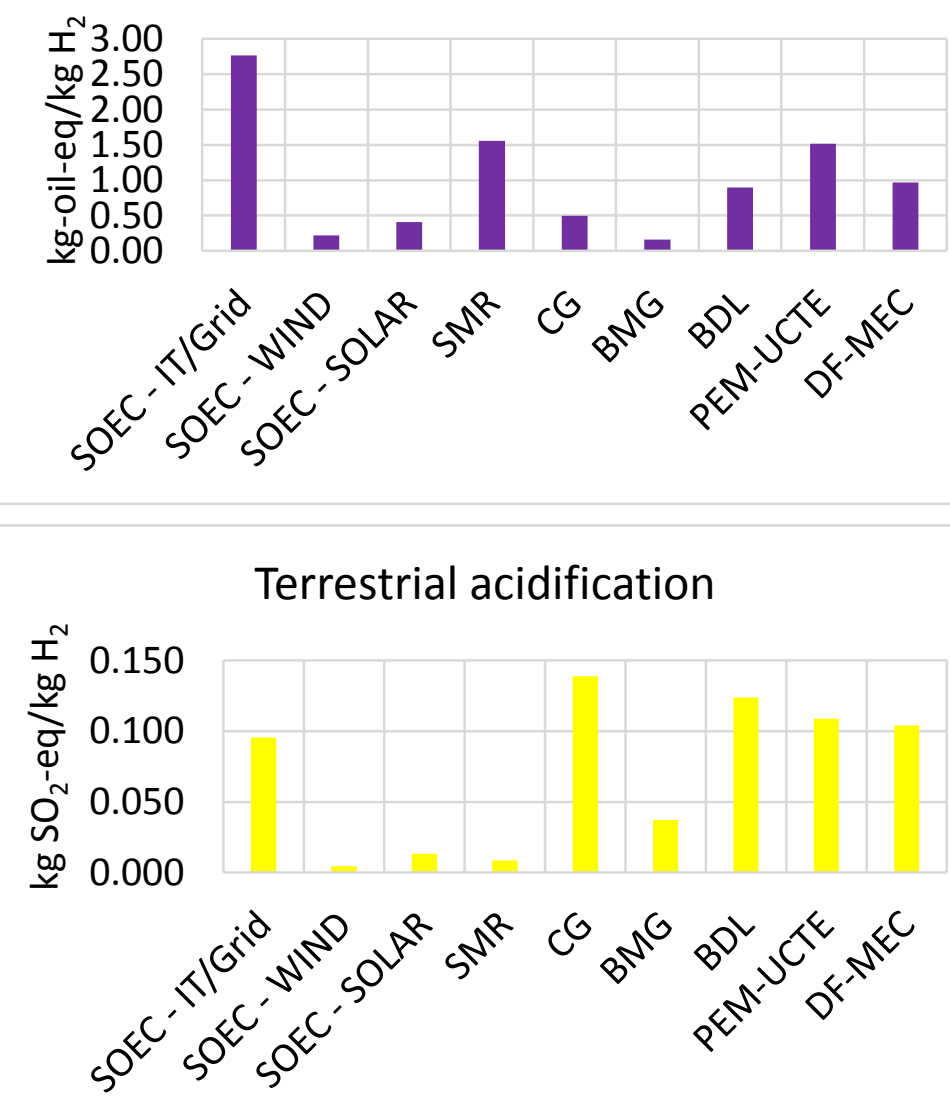

Ecosystems

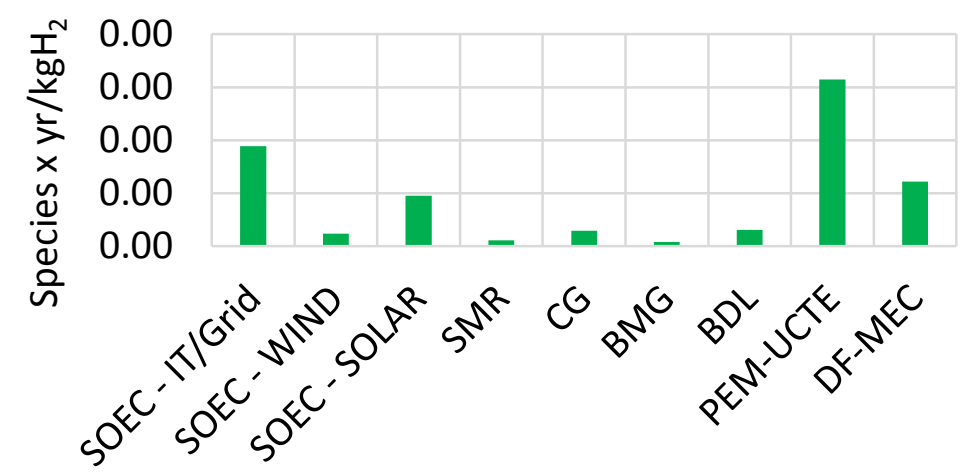

Global warming potential

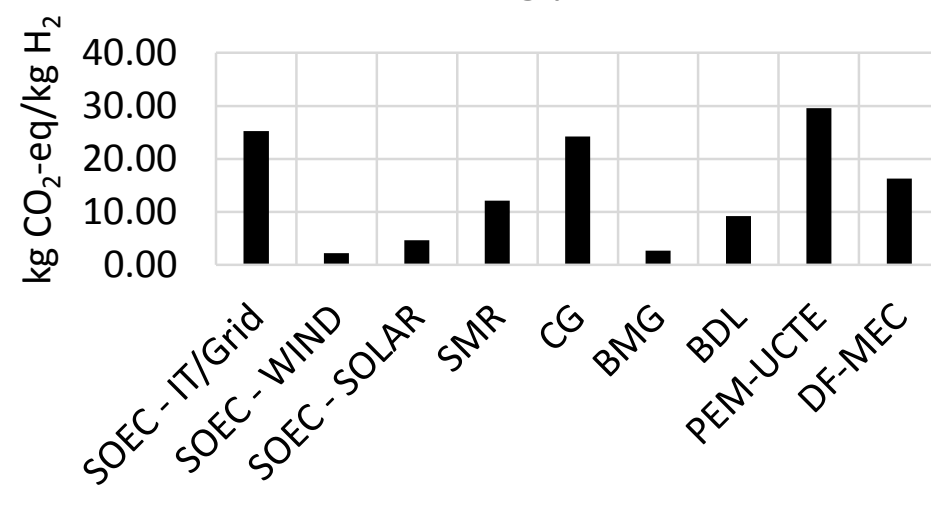

\section{Water consumption potential}

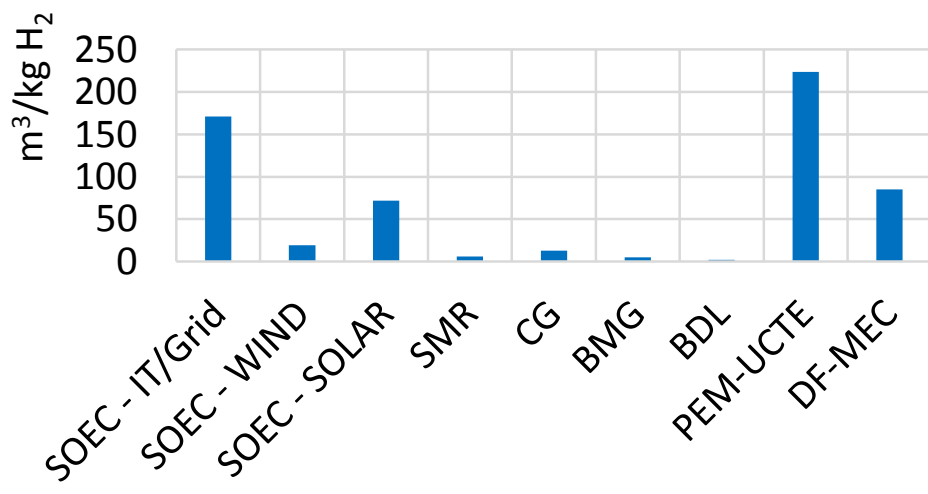




\section{Table captions:}

Table 1. Input-output flows for production of $1 \mathrm{~kg}$ of hydrogen with high-temperature solid oxide electrolysis (SOEC).

Table 2. Midpoint and endpoint environmental performance indicators of HTE-SOEC hydrogen production (data referred to $1 \mathrm{~kg} \mathrm{H}_{2}$ ).

Table 3. Weighted contribution of midpoint categories on the endpoint level for each electricity pathway.

Table 4. Country-level ReCiPe2016 life cycle impacts for grid-based electrolysis based on SOEC (data referred to $1 \mathrm{~kg} \mathrm{H}_{2}$ ). 
Table 1. Input-output flows for production of $1 \mathrm{~kg}$ of hydrogen with high-temperature solid oxide electrolysis (SOEC).

\begin{tabular}{llcc}
\hline Unit of product & Material & Data input & $\mathrm{Unit}$ \\
\hline \multirow{5}{*}{ Operation } & Deionized water & 10.84 & $\mathrm{~kg}$ \\
& Electricity supply a & 40.3 & $\mathrm{kWh}$ \\
& Heat, Natural gas, at boiler modulating & 5.24 & $\mathrm{kWh}$ \\
& Products/Services Hydrogen, at SOEC plant & 1 & $\mathrm{~kg}$ \\
& By-Product Oxygen, at SOEC plant & 7.8 & $\mathrm{~kg}$ \\
\hline & Yttria stabilized zirconia (YSZ) & $4.41 \times 10^{-4}$ & $\mathrm{~kg}$ \\
& Lanthanum Strontium Manganite (LSM) & $2.64 \times 10^{-4}$ & $\mathrm{~kg}$ \\
& Nickel Oxide (Nickel, 99.5\%, at plant) & $2.22 \times 10^{-4}$ & $\mathrm{~kg}$ \\
& Ethanol, at plant/RER & $6.49 \times 10^{-4}$ & $\mathrm{~kg}$ \\
& Polyethyleneglycol, at plant/RER & $1.30 \times 10^{-4}$ & $\mathrm{~kg}$ \\
& 1-butanol, propylene hydroformylation, at plant/RER & $7.35 \times 10^{-5}$ & $\mathrm{~kg}$ \\
& Phthalic anhydride, at plant/RER & $7.35 \times 10^{-5}$ & $\mathrm{~kg}$ \\
& Chromium, at regional storage/RER & $8.10 \times 10^{-3}$ & $\mathrm{~kg}$ \\
& Chromium steel 18/8, at plant/RER & $4.68 \times 10^{-3}$ & $\mathrm{~kg}$ \\
& Sheet rolling, chromium steel/RER & $4.68 \times 10^{-3}$ & $\mathrm{~kg}$ \\
& Electricity, medium voltage, production UCTE, at grid & $1.90 \times 10^{-4}$ & $\mathrm{MWh}$ \\
& Alumina-silica insulation material & $1.30 \times 10^{-3}$ & $\mathrm{~kg}$ \\
& Transport, all modes ${ }^{\mathrm{b}}$ & $3.19 \times 10^{-3}$ & $\mathrm{tkm}$ \\
\hline Reinforcing Steel, at plant/RER & $1.32 \times 10^{-4}$ & $\mathrm{~kg}$ \\
& Sheet rolling, steel/RER & $1.32 \times 10^{-4}$ & $\mathrm{~kg}$ \\
Chromium, at regional storage/RER & $5.39 \times 10^{-4}$ & $\mathrm{~kg}$ \\
Aluminium, at plant/RER & $5.82 \times 10^{-5}$ & $\mathrm{~kg}$ \\
Copper, at regional storage/RER & $2.81 \times 10^{-4}$ & $\mathrm{~kg}$ \\
Electricity, medium voltage, production UCTE, at grid & $1.15 \times 10^{-6}$ & $\mathrm{MWh}$ \\
Transport, all modes b & $2.02 \times 10^{-4}$ & $\mathrm{tkm}$ \\
Heating, sanitary equipment Cogen unit 160kWe/RER & $1.17 \times 10^{-6}$ & $\mathrm{MJ}$ \\
Construction work, Cogen unit 160kWe/RER & $5.46 \times 10^{-6}$ & $\mathrm{unit}$ \\
Light fuel oil, boiler 100kW, non-modulating/RER & $1.30 \times 10^{-2}$ & $\mathrm{MJ}$ \\
Building, multi-storey/RER & $4.90 \times 10^{-6}$ & $\mathrm{~m}{ }^{3}$ \\
Building, hall, steel construction/CH & $8.07 \times 10^{-7}$ & $\mathrm{~m}{ }^{2}$ \\
\hline
\end{tabular}

${ }^{a}$ Lifecycle unit processes linked to the Ecoinvent: Grid - Electricity, medium voltage, at grid/IT; Nuclear - Electricity, nuclear, at power plant/UCTE; Wind power - Electricity, at wind power plant/RER; Natural gas, high pressure, at consumer/RER; Solar power - electricity, production mix photovoltaic, at plant/IT; Electricity, hydropower, at power plant/IT; Electricity, hard coal, at power plant/IT; Water, deionized, at plant/CH;

${ }^{\mathrm{b}}$ A distance of $200 \mathrm{~km}$ was considered for all transportation systems: i) Transoceanic freight ship; ii) Freight, rail; iii) lorry >16t, fleet average; iv) Lorry 3.5-16t, fleet average; v) Passenger car; vi) Barge 
Table 2. Midpoint and endpoint environmental performance indicators of HTE-SOEC hydrogen production (data referred to $\left.1 \mathrm{~kg} \mathrm{H}_{2}\right)$.

\begin{tabular}{|c|c|c|c|c|c|c|c|c|c|}
\hline \multirow{2}{*}{$\begin{array}{l}\text { Impact } \\
\text { Category }\end{array}$} & \multirow[b]{2}{*}{ Unit } & \multicolumn{8}{|c|}{ Electricity source } \\
\hline & & $\begin{array}{l}\text { ITALIAN } \\
\text { GRID }\end{array}$ & COAL & NATURAL GAS & NUCLEAR & WIND & SOLAR & BIOMASS & HYDRO \\
\hline \multicolumn{10}{|c|}{ Midpoint environmental impact categories } \\
\hline GWP & $\mathrm{kg} \mathrm{CO}_{2}$-eq & 25.64 & 43.95 & 28.93 & 2.11 & 2.26 & 4.63 & 14.36 & 0.72 \\
\hline ODP & kg CFC11-eq & $1.19 \times 10^{-5}$ & $1.23 \times 10^{-5}$ & $1.02 \times 10^{-5}$ & $1.05 \times 10^{-6}$ & $7.79 \times 10^{-7}$ & $2.21 \times 10^{-6}$ & $3.80 \times 10^{-5}$ & $2.61 \times 10^{-7}$ \\
\hline IRP & $\mathrm{kBq}$ Co60-eq & 3.92 & 0.96 & 0.28 & 44.73 & 0.30 & 0.98 & 1.76 & 0.25 \\
\hline HOFP & $\mathrm{kg} \mathrm{NO}-\mathrm{eq}$ & 0.0501 & 0.1201 & 0.0369 & 0.0029 & 0.0026 & 0.0080 & 0.0124 & 0.0015 \\
\hline PMFP & kg PM2.5-eq & 0.0256 & 0.0643 & 0.0050 & 0.0020 & 0.0016 & 0.0042 & 0.0050 & 0.0010 \\
\hline EOFP & $\mathrm{kg} \mathrm{NO}-\mathrm{eq}$ & 0.0511 & 0.1209 & 0.0384 & 0.0032 & 0.0029 & 0.0085 & 0.0129 & 0.0017 \\
\hline TAP & $\mathrm{kg} \mathrm{SO}_{2}-\mathrm{eq}$ & 0.0955 & 0.2309 & 0.0274 & 0.0045 & 0.0044 & 0.0135 & 0.0297 & 0.0025 \\
\hline FEP & kg P-eq & 0.00601 & 0,02995 & 0,00050 & 0,00052 & 0,00065 & 0,00268 & 0,00095 & 0,00040 \\
\hline TETP & $\mathrm{kg} 1.4 \mathrm{DCB}-\mathrm{eq}$ & 0.0091 & 0.0040 & 0.0010 & 0.0037 & 0.0017 & 0.0211 & 0.0026 & 0.0006 \\
\hline FETP & kg 1.4DCB-eq & 0.214 & 0.877 & 0.031 & 0.060 & 0.058 & 0.284 & 0.129 & 0.024 \\
\hline METP & kg 1.4DCB-eq & 0.32 & 1.22 & 0.05 & 0.09 & 0.08 & 0.43 & 0.18 & 0.04 \\
\hline HTPc & kg 1.4DCB-eq & 0.89 & 2.23 & 0.54 & 0.52 & 0.60 & 0.71 & 0.60 & 0.46 \\
\hline HTPnc & $\mathrm{kg} 1.4 \mathrm{DCB}-\mathrm{eq}$ & 222.01 & 906.17 & 26.50 & 49.00 & 52.99 & 338.01 & 94.08 & 19.15 \\
\hline LOP & $\mathrm{m}^{2} \times$ y crop-eq & 0.083 & 0.424 & 0.014 & 0.016 & 0.033 & 0.053 & 0.037 & 0.009 \\
\hline SOP & $\mathrm{kg} \mathrm{Cu}-\mathrm{eq}$ & 0.030 & 0.026 & 0.022 & 0.048 & 0.067 & 0.076 & 0.031 & 0.022 \\
\hline FFP & kg oil-eq & 7.59 & 10.65 & 10.41 & 0.70 & 0.75 & 1.39 & 1.77 & 0.18 \\
\hline WCP & $\mathrm{m}^{3}$ & 171.07 & 25.82 & 16.73 & 17.46 & 19.39 & 71.79 & 35.31 & 716.33 \\
\hline \multicolumn{10}{|c|}{ Endpoint environmental impact categories } \\
\hline $\mathrm{HH}$ & DALY & $3.40 \times 10^{-4}$ & $1.46 \times 10^{-4}$ & $6.30 \times 10^{-5}$ & $3.83 \times 10^{-5}$ & $4.24 \times 10^{-5}$ & $1.65 \times 10^{-4}$ & $9.14 \times 10^{-5}$ & $1.53 \times 10^{-3}$ \\
\hline EQ & Species $\times y$ & $1.89 \times 10^{-6}$ & $5.24 \times 10^{-7}$ & $2.83 \times 10^{-7}$ & $2.09 \times 10^{-7}$ & $2.35 \times 10^{-7}$ & $9.55 \times 10^{-7}$ & $4.91 \times 10^{-7}$ & $9.29 \times 10^{-6}$ \\
\hline $\mathrm{RA}$ & $\$$ & 2.767 & 1.291 & 3.707 & 0.236 & 0.248 & 0.441 & 0.61 & 0.215 \\
\hline
\end{tabular}


Table 3. Weighted contribution of midpoint categories on the endpoint level for each electricity pathway.

\begin{tabular}{|c|c|c|c|c|c|c|c|c|}
\hline Midpoint categories & GRID & COAL & NG & NUCLEAR & WIND & SOLAR & BIOMASS & HYDRO \\
\hline \multicolumn{9}{|c|}{ Human Health (DALY) } \\
\hline GWP & $7.75 \%$ & $27.94 \%$ & $42.62 \%$ & $4.87 \%$ & $4.72 \%$ & $2.55 \%$ & $14.52 \%$ & $0.11 \%$ \\
\hline ODP & $0.00 \%$ & $0.00 \%$ & $0.01 \%$ & $0.00 \%$ & $0.00 \%$ & $0.00 \%$ & $0.02 \%$ & $0.00 \%$ \\
\hline IRP & $0.00 \%$ & $0.01 \%$ & $0.00 \%$ & $1.00 \%$ & $0.01 \%$ & $0.00 \%$ & $0.02 \%$ & $0.00 \%$ \\
\hline HOFP & $0.01 \%$ & $0.07 \%$ & $0.05 \%$ & $0.01 \%$ & $0.01 \%$ & $0.00 \%$ & $0.01 \%$ & $0.00 \%$ \\
\hline PMPF & $4.90 \%$ & $27.64 \%$ & $4.84 \%$ & $3.09 \%$ & $2.19 \%$ & $1.53 \%$ & $3.31 \%$ & $0.04 \%$ \\
\hline HTPc & $0.78 \%$ & $4.92 \%$ & $2.46 \%$ & $3.91 \%$ & $4.13 \%$ & $1.28 \%$ & $1.92 \%$ & $0.09 \%$ \\
\hline HTPnc & $0.40 \%$ & $4.12 \%$ & $0.24 \%$ & $0.80 \%$ & $0.78 \%$ & $1.35 \%$ & $0.66 \%$ & $0.01 \%$ \\
\hline WCP & $86.15 \%$ & $35.30 \%$ & $49.77 \%$ & $86.33 \%$ & $88.16 \%$ & $93.28 \%$ & $79.54 \%$ & $99.75 \%$ \\
\hline \multicolumn{9}{|c|}{ Ecosystems $[$ Species $\times$ y] } \\
\hline GWP & $4.2 \%$ & $23.5 \%$ & $28.7 \%$ & $2.7 \%$ & $2.6 \%$ & $1.3 \%$ & $8.1 \%$ & $0.1 \%$ \\
\hline EOFP & $0.4 \%$ & $3.0 \%$ & $1.7 \%$ & $0.2 \%$ & $0.1 \%$ & $0.1 \%$ & $0.3 \%$ & $0.0 \%$ \\
\hline TAP & $1.1 \%$ & $9.3 \%$ & $2.0 \%$ & $0.4 \%$ & $0.4 \%$ & $0.3 \%$ & $1.3 \%$ & $0.0 \%$ \\
\hline FEP & $0.2 \%$ & $3.5 \%$ & $0.1 \%$ & $0.1 \%$ & $0.2 \%$ & $0.2 \%$ & $0.1 \%$ & $0.0 \%$ \\
\hline TETP & $0.0272 \%$ & $0.0398 \%$ & $0.0164 \%$ & $0.0923 \%$ & $0.0374 \%$ & $0.1186 \%$ & $0.0268 \%$ & $0.0003 \%$ \\
\hline FETP & $0.0071 \%$ & $0.1156 \%$ & $0.0066 \%$ & $0.0185 \%$ & $0.0158 \%$ & $0.0203 \%$ & $0.0176 \%$ & $0.0002 \%$ \\
\hline METP & $0.0017 \%$ & $0.0245 \%$ & $0.0017 \%$ & $0.0042 \%$ & $0.0035 \%$ & $0.0046 \%$ & $0.0037 \%$ & $0.0000 \%$ \\
\hline LOP & $0.0 \%$ & $0.7 \%$ & $0.0 \%$ & $0.1 \%$ & $0.1 \%$ & $0.0 \%$ & $0.1 \%$ & $0.0 \%$ \\
\hline WCP & $94.0 \%$ & $59.8 \%$ & $67.4 \%$ & $96.4 \%$ & $96.6 \%$ & $97.9 \%$ & $90.0 \%$ & $99.9 \%$ \\
\hline \multicolumn{9}{|c|}{ Resources [\$] } \\
\hline SOP & $0.2 \%$ & $0.4 \%$ & $0.1 \%$ & $4.5 \%$ & $6.1 \%$ & $3.9 \%$ & $1.1 \%$ & $2.1 \%$ \\
\hline FFP & $99.8 \%$ & $99.6 \%$ & $99.9 \%$ & $95.5 \%$ & $93.9 \%$ & $96.1 \%$ & $98.9 \%$ & $97.9 \%$ \\
\hline
\end{tabular}

${ }^{\mathrm{a}}$ Global warming potential (GWP); Stratospheric ozone depletion (ODP); Ionizing radiation (IRP); Photochemical oxidant formation: human health (HOFP); Photochemical oxidant formation: ecosystem quality (EOFP); Human toxicity potential: cancer $\left(\mathrm{HTP}_{\mathrm{c}}\right)$; Human toxicity potential: non-cancer $\left(\mathrm{HTP}_{\mathrm{nc}}\right)$; Terrestrial ecotoxicity $(\mathrm{TETP})$; Freshwater ecotoxicity (FETP); Marine ecotoxicity (METP); Freshwater eutrophication potential (FEP); Fine particulate matter formation (PMFP); Terrestrial acidification (TAP); Land use (LOP); Water consumption potential (WCP); Mineral resource scarcity (SOP); Fossil resource scarcity (FFP); 
Table 4. Country-level ReCiPe2016 life cycle impacts for grid-based electrolysis based on SOEC.

\begin{tabular}{|c|c|c|c|c|c|c|c|c|c|c|c|}
\hline Impact category & Unit & $\vec{\Xi}$ & 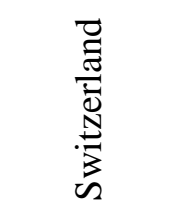 & 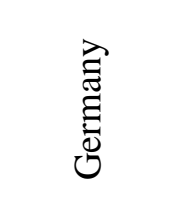 & 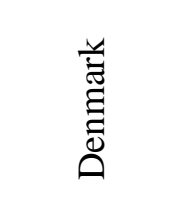 & 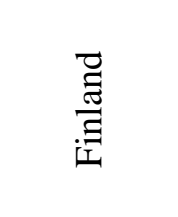 & 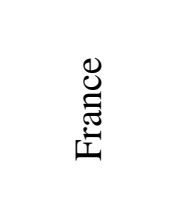 & $\begin{array}{l}\text { च } \\
\text { ज्ञ } \\
\overline{0} \\
\overline{0} \\
\overline{0}\end{array}$ & $\begin{array}{l}\overrightarrow{\tilde{z}} \\
\stackrel{0}{0} \\
\text { z }\end{array}$ & $\begin{array}{l}\overrightarrow{\tilde{J}} \\
\frac{\pi}{0} \\
0\end{array}$ & 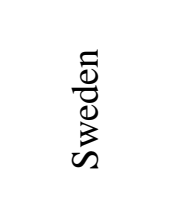 \\
\hline GWP & $\mathrm{kgCO}_{2}$-eq & 25.64 & 7.18 & 28.85 & 25.81 & 20.51 & 5.66 & 29.62 & 3.31 & 48.24 & 5.44 \\
\hline ODP & kg CFC11-eq & $1.19 \times 10^{-5}$ & $4.77 \times 10^{-6}$ & $1.18 \times 10^{-5}$ & $1.39 \times 10^{-5}$ & $1.09 \times 10^{-5}$ & $3.93 \times 10^{-6}$ & $1.19 \times 10^{-5}$ & $3.57 \times 10^{-6}$ & $6.88 \times 10^{-6}$ & $5.06 \times 10^{-6}$ \\
\hline IRP & kBq Co60-eq & 3.92 & 24.97 & 12.53 & 3.18 & 12.19 & 38.60 & 4.40 & 2.37 & 1.28 & 21.73 \\
\hline HOFP & $\mathrm{kg} \mathrm{NO}_{\mathrm{x}}$-eq & 0.0501 & 0.011 & 0.025 & 0.030 & 0.032 & 0.012 & 0.037 & 0.004 & 0.074 & 0.011 \\
\hline TAP & $\mathrm{kg} \mathrm{SO}_{2}$-eq & 0.0225 & 0.0321 & 0.0504 & 0.0475 & 0.0203 & 0.0333 & 0.0063 & 0.2200 & 0.22 & 0.0225 \\
\hline FEP & kg P-eq & 0.0049 & 0.0329 & 0.0072 & 0.0078 & 0.0022 & 0.0113 & 0.0008 & 0.0491 & 0.05 & 0.0049 \\
\hline TETP & $\mathrm{kg} 1.4 \mathrm{DCB}-\mathrm{eq}$ & 0.0057 & 0.0052 & 0.0055 & 0.0065 & 0.0064 & 0.0046 & 0.0035 & 0.0094 & 0.00937 & 0.0057 \\
\hline FETP & $\mathrm{kg} 1.4 \mathrm{DCB}-\mathrm{eq}$ & 0.214 & 0.18 & 0.84 & 0.27 & 0.28 & 0.13 & 0.35 & 0.06 & 1.39 & 0.11 \\
\hline METP & $\mathrm{kg} 1.4 \mathrm{DCB}-\mathrm{eq}$ & 0.32 & 0.26 & 1.16 & 0.39 & 0.41 & 0.19 & 0.52 & 0.09 & 1.92 & 0.17 \\
\hline HTPc & $\mathrm{kg}$ 1.4DCB-eq & 0.89 & 0.79 & 2.07 & 0.99 & 1.00 & 0.67 & 1.12 & 0.55 & 3.52 & 0.64 \\
\hline $\mathrm{HH}$ & DALY & $3.40 \times 10^{-4}$ & $7.44 \times 10^{-4}$ & $2.60 \times 10^{-4}$ & $2.06 \times 10^{-4}$ & $3.50 \times 10^{-4}$ & $4.30 \times 10^{-4}$ & $1.02 \times 10^{-4}$ & $2.31 \times 10^{-4}$ & $2.32 \times 10^{-4}$ & $1.31 \times 10^{-3}$ \\
\hline EQ & Species $\times y$ & $1.89 \times 10^{-6}$ & $4.46 \times 10^{-6}$ & $1.42 \times 10^{-6}$ & $1.11 \times 10^{-6}$ & $1.98 \times 10^{-6}$ & $2.57 \times 10^{-6}$ & $4.89 \times 10^{-7}$ & $1.38 \times 10^{-6}$ & $9.87 \times 10^{-7}$ & $7.92 \times 10^{-6}$ \\
\hline RA & $\$$ & 2.767 & 0.50 & 0.91 & 1.39 & 0.91 & 0.43 & 2.46 & 0.28 & 1.02 & 0.37 \\
\hline
\end{tabular}

${ }^{\mathrm{a}}$ Global warming potential (GWP); Stratospheric ozone depletion (ODP); Ionizing radiation (IRP); Photochemical oxidant formation: human health (HOFP); Photochemical oxidant formation: ecosystem quality (EOFP); Human toxicity potential: cancer $\left(\mathrm{HTP}_{\mathrm{c}}\right)$; Human toxicity potential: non-cancer $\left(\mathrm{HTP}_{\mathrm{nc}}\right.$ ); Terrestrial ecotoxicity $(\mathrm{TETP})$; Freshwater ecotoxicity (FETP); Marine ecotoxicity (METP); Freshwater eutrophication potential (FEP); Fine particulate matter formation (PMFP); Terrestrial acidification (TAP 100); Land use (LOP); Water consumption potential (WCP); Mineral resource scarcity (SOP); Fossil resource scarcity (FFP); Human health (HH); Ecosystem quality (EQ); Resource scarcity (RA); 